\title{
Mechanisms of enhanced ocean surface warming in the Kuroshio region for 1951-2010
}

\author{
Masaki Toda $^{1} \cdot$ Masahiro Watanabe $^{1}$
}

Received: 23 August 2019 / Accepted: 28 March 2020 / Published online: 7 April 2020

(c) The Author(s) 2020

\begin{abstract}
Since the early twentieth century, observations have shown that the ocean surface has warmed almost globally, but the rate of sea surface temperature (SST) rise in the Kuroshio region (KR) has been twice that of the global-mean. This study focuses on the mechanisms driving long-term changes in SST in the KR during the period 1951-2010 using observations, reanalysis data, and 10-member ensembles of historical simulations based on a global climate model (GCM) called MIROC 5.2. The observational data indicates that SST in the KR slightly decreased until around 1980, but rapidly increased afterwards. The MIROC5.2 historical experiment reproduced the observed multidecadal changes in the KR SST, and a signalto-noise analysis showed that one third to half of the changes were attributable to a forced component, represented by the ensemble mean. Comparison of historical runs with another ensemble in which sulfate aerosols were fixed at preindustrial levels, highlighted that multidecadal SST changes in the KR were primarily driven by sulfate aerosols, contributing to the warming for 1981-2010 as much as greenhouse gases. Analyses of the MIROC5.2 ensemble mean revealed that the key factor for enhanced warming after the 1980s in the KR was a high-pressure trend over the North Pacific. This is because it advects warm air to the northwestern Pacific in the lower troposphere and causes a northward shift in the Kuroshio current. The presence of this mechanism was supported by a significant correlation between SST trends in the KR and high-pressure trends over the North Pacific based on historical simulations from 27 GCMs, and a large ensemble of historical simulations using MIROC6. These results demonstrate the importance of an externally forced atmospheric circulation response over the North Pacific as it relates to enhanced ocean surface warming in the KR.
\end{abstract}

\section{Introduction}

Changes in sea surface temperature (SST) patterns are known to be a primary driver of changes in precipitation and atmospheric circulation under global warming (Chadwick et al. 2014; Xie et al. 2010). Much of the excess energy in the climate system since 1955 is estimated to be absorbed by oceans (IPCC 2013), inevitably accompanying SST increases over most of the globe. However, it is still challenging to precisely predict regional changes in SST in the future climate because of the complexity in the atmosphere-ocean coupled system. For example, there are two types of changes in the tropical Pacific SST in general circulation models (GCMs); an El Niño like SST change

Masaki Toda

m_toda@aori.u-tokyo.ac.jp

1 Atmosphere and Ocean Research Institute, The University of Tokyo, 5-1-5 Kashiwanoha, Kashiwa, Chiba 277-8568, Japan pattern, in which SST in the eastern tropical Pacific Ocean increases more than the western Pacific, and a La Niña like warming pattern (Collins et al. 2010; Andrews et al. 2014).

There are long term measurements of SST, and several datasets commonly show that the global-mean SST has increased during the twentieth century. Of particular interest is SST in the Kuroshio region (KR), which has increased twice as much as the global-mean SST. The linear trend of globalmean SST from 1891-2016 was $0.53 \mathrm{~K}$ per century, but in the KR the SST trend was $1.09 \mathrm{~K}$ per century (Japan Meteorological Agency 2018). While changes in SST in the KR may be driven by changes in the Kuroshio current, they could also be affected by atmospheric temperature changes over the eastern side of the Eurasia continent in association with changes in the winter monsoon (Liu et al. 2005). This geographical feature may give rise to multiple factors that can affect changes in SST in the KR. As the ocean in the KR acts as a heat reservoir that maintains weather over East Asia, understanding the mechanism of long-term changes in the SST is important to detect 
and attribute weather conditions over these regions since the twentieth century.

Several studies have investigated possible changes in the western boundary currents under global warming scenarios using global warming experiments. Saenko et al. (2005) showed that western boundary currents migrate poleward from their global warming experiments, while Sakamoto et al. (2005) indicated a strengthening of the Kuroshio current without the latitudinal shift of the currents. This research suggests that changes in the Kuroshio current could occur in response to future changes in radiative forcing. However, the nature of the change to the western boundary currents is dependent on the climate model used in the global warming experiments. Furthermore, it is difficult to detect changes in the Kuroshio current during the twentieth century due to the lack of longterm measurements of ocean currents.

Wu et al. (2012) demonstrated that the observed SST during the twentieth century increased in areas of the western boundary currents compared to other parts of the ocean. They also suggested that the large increase in SST around the western boundary currents occurred in association with a strengthening and a poleward migration of the currents. However, the ocean reanalysis data employed in their study includes considerable potential errors and may not represent reliable long-term changes, leading to conclusions that are insufficiently robust.

The research to date, suggests that there is a possibility that changes in SST in the KR during the twentieth century were at in part driven by changes in the Kuroshio current. However, there is little research that comprehensively attributes the SST change in the KR to external forcing and internal variability, both of which would have affected the SST by alternating circulation in the atmosphere and ocean. As such, this study investigates the mechanisms of multidecadal SST changes in the KR from the mid twentieth century using observations and ensemble climate simulations by a GCM.

This paper is organized as follows. Section 2 describes the datasets, model, and numerical experiments. Section 3 examines the characteristics of SST changes in the $\mathrm{KR}$, including the contribution of external forcing to SST changes. In Sect. 4, detailed mechanisms of long-term SST changes in response to forcing are clarified using the ensemble of historical simulations. This is followed by a validation of the mechanisms using multi-model simulations and reanalysis data in Sect. 5. Section 6 provides a summary and discussion.

\section{Methods}

\subsection{Definition of the KR}

In this study, the KR refers to a region that includes the Kuroshio and Oyashio currents, Sea of Japan (East Sea), and East China Sea, as represented by a rectangular box $\left(25^{\circ} \mathrm{N}-47^{\circ} \mathrm{N}, 120^{\circ} \mathrm{E}-155^{\circ} \mathrm{E}\right)$ shown in Fig. 1a. Between 1901-2000, the SST increased by $1.1 \mathrm{~K}$ in this region, which is a considerably large increase compared to the warming witnessed in the other areas of the Pacific (Fig. 1a).

\subsection{Observational data}

Several SST datasets are available from the middle of the nineteenth century. However, measurement methods vary depending on the period and analysis methods adopted in these datasets. As such, the reliability of earlier datasets is questionable. We investigated the time after which different datasets agree with each other. In this study, we used three datasets; COBE-SST (Ishii et al. 2005), Hadley Centre Sea Ice and SST (HadISST, Rayner et al. 2003), and National Oceanic and Atmospheric Administration Extended SST

(a)

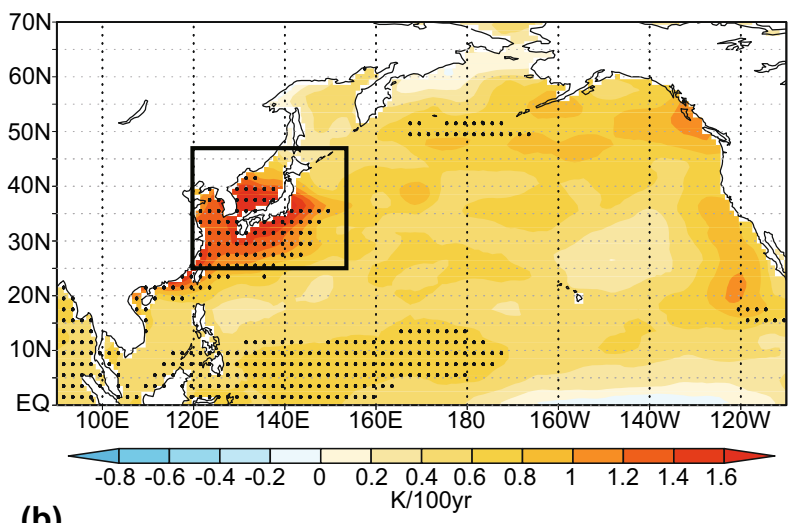

(b)

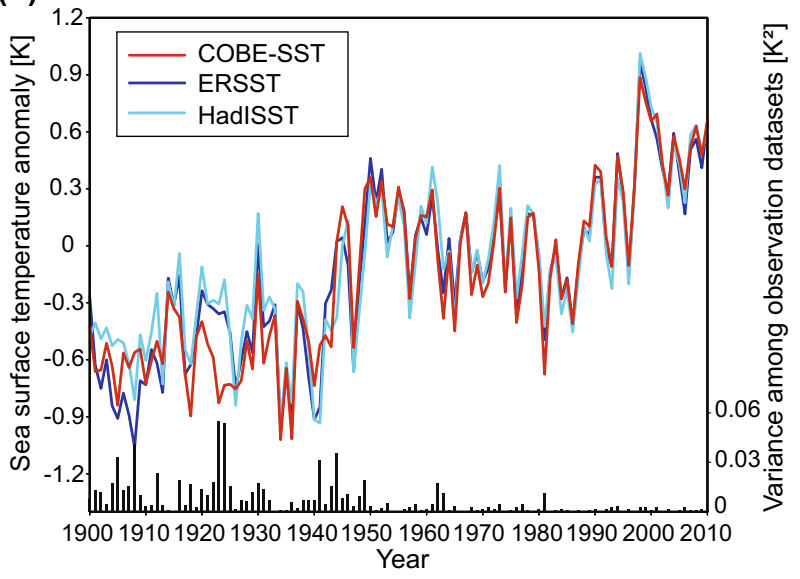

Fig. 1 a Observed sea surface temperature (SST) trend (K per century) for 1901-2000 based on COBE-SST. The dots indicate the value that is statistically significant at the $95 \%$ confidence level. The spatial extent of the Kuroshio region (KR) is indicated by the black box $\left(25^{\circ}-47^{\circ} \mathrm{N}, 120-155^{\circ} \mathrm{E}\right)$. b The time series of the observed annual-mean SST averaged in the KR from the three datasets (colored curves). The bar graph illustrates the variance among the three observational datasets 
(ERSST, Smith et al. 2008). The horizontal resolution was $1^{\circ} \times 1^{\circ}$ in COBE-SST and HadISST, and $2^{\circ} \times 2^{\circ}$ in ERSST. Figure $1 \mathrm{~b}$ presents a time series of the SST anomaly, relative to the 1900-2010 climatology, averaged in the KR for the three datasets and also includes the variance among them. It is evident that the discrepancy across the datasets is large prior to 1950. As such, we restricted the analysis of the COBE-SST data to post-1951.

We also analyzed atmospheric data of winds, temperature, and geopotential height derived from the Japanese 55-year Reanalysis (JRA-55, Kobayashi et al. 2015). The JRA-55 includes monthly data since January 1958, with a horizontal resolution of $1.25^{\circ} \times 1.25^{\circ}$ and on 37 pressure levels.

\subsection{Model and numerical experiments}

We used the Model for Interdisciplinary Research on Climate version 5.2 (MIROC5.2) CGCM (Watanabe et al. 2014), which was cooperatively developed at the Atmosphere and Ocean Research Institute (AORI) of The University of Tokyo, the National Institute for Environmental Studies (NIES), and the Japan Agency for Marine Earth Science and Technology (JAMSTEC). The resolution of the atmospheric model was T85 (approximately $150 \mathrm{~km}$ ) and 40 vertical levels. The oceanic component has a $1^{\circ}$ longitudinal grid spacing. The meridional grid spacing varies from approximately $0.5^{\circ}$ near the equator to $1^{\circ}$ in the mid-latitudes. There are 63 vertical levels, and the lowermost level was located at a depth of $6300 \mathrm{~m}$.

We conducted two sets of 10-member simulations from 1921 to 2015 using the MIROC5.2 CGCM. One was a historical experiment (HIST) in which all the external conditions were given following the Coupled Model Intercomparison Project (CMIP5) experimental set up before 2005 and the Representative Concentration Pathway 4.5 (RCP4.5) run after 2006 (Taylor et al. 2011). The model was branched off from the official CMIP5 historical run beginning in 1850, and used slightly different initial conditions to create the ensemble post-1921. The other experiment, referred to as SO2CONST (Takahashi and Watanabe 2016), was the same as the HIST, except that emissions of sulfate aerosols (both natural and anthropogenic) were fixed at 1850 levels. Given that sulfate aerosols are an important driver of large-scale SST pattern changes (Booth et al. 2012; Xie and Xiang 2013; Watanabe and Tatebe 2019), we compared HIST and SO2CONST to identify the contribution of sulfate aerosols in forcing SST changes over 1951-2010. In SO2CONST, forcing other than sulfate aerosols was included, but the greenhouse gasses (GHGs) effect dominated. In this study, we assumed that SO2CONST represents a response to forcing by GHGs. All numerical experiments analyzed in this study are summarized in Table 1.

\subsection{CMIP5 historical simulations and a large ensemble historical run by MIROC6}

To validate the mechanisms observed in MIROC5.2 CGCM, we performed an analysis of historical simulations using 22 GCMs in the CMIP5 for 1951-2010. We used run01 for models presented in Table 2. The RCP4.5 run was connected to the historical run to extend the analysis period beyond 2006. The horizontal resolution of SST in each model was re-gridded to $2.5^{\circ} \times 2.5^{\circ}$ prior to the analysis.

In addition to the CMIP5 multi model analysis, we also performed an analysis of large ensemble historical simulations of MIROC6 with 50 ensemble members over 1951-2010 (Tatebe et al. 2019). MIROC6 is a slight updated version of MIROC5.2, with an identical horizontal resolution and has been used for CMIP6 experiments (Eyring et al. 2016). The SST data from the large ensemble was re-gridded to $1^{\circ} \times 1^{\circ}$.

\subsection{Analysis procedure}

We used annual-mean datasets other than the analysis for seasonality. For most time series, an anomaly was defined as the deviation from the average over the 1951-2010 period. In some analyses, we applied a low-pass filter to the anomaly fields in order to eliminate variations shorter than 10 years.

Using the MIROC5.2 ensembles, we decomposed SST anomalies into an externally forced component defined by the respective ensemble mean and internal variability represented by deviations from the ensemble mean. As described above, HIST includes all external forcing and SO2CONST includes external forcing other than sulfate aerosols. To evaluate the role of sulfate aerosol forcing, we defined the responses to sulfate aerosols as HIST minus SO2CONST, herein referred as AERO.

Table 1 Experiments conducted in this study by using MIROC 5.2 CGCM

\begin{tabular}{lll}
\hline Experiment name & GHGs & Sulfate aerosols \\
\hline HIST & Historical & Historical \\
SO2CONST & Historical & Pre-industrial \\
\hline
\end{tabular}

Each experiment had ten ensemble members and was integrated from 1921 to 2015 
Table 2 CMIP5 GCMs used in this study and sea surface temperature (SST) trends for 1951-2010 in each model

\begin{tabular}{|c|c|c|c|c|}
\hline & GCMs & $\begin{array}{l}\text { SST trend in the } \\
\text { KR }[K / 100 \mathrm{yr}]\end{array}$ & $\begin{array}{l}\text { Global-mean SST } \\
\text { trend }[\mathrm{K} / 100 \mathrm{yr}]\end{array}$ & $\begin{array}{l}\text { Ratio of SST trends in } \\
\text { the KR to the global- } \\
\text { mean }\end{array}$ \\
\hline 1 & $\mathrm{BCC}$ & $1.57 \pm 0.12$ & $1.29 \pm 0.09$ & $1.22 \pm 0.13$ \\
\hline 2 & CAMESM2 & $1.24 \pm 0.11$ & $1.30 \pm 0.09$ & $0.95 \pm 0.11$ \\
\hline 3 & CCSM & $1.75 \pm 0.14$ & $1.25 \pm 0.09$ & $1.40 \pm 0.15$ \\
\hline 4 & $\mathrm{CMCC}$ & $1.07 \pm 0.09$ & $0.80 \pm 0.06$ & $1.33 \pm 0.15$ \\
\hline 5 & CNRM-CM5 & $0.52 \pm 0.07$ & $0.76 \pm 0.06$ & $0.68 \pm 0.11$ \\
\hline 6 & CSIRO-MK3.6 & $1.01 \pm 0.10$ & $0.26 \pm 0.03$ & $3.90 \pm 0.6$ \\
\hline 7 & FGOALS-G2 & $1.61 \pm 0.12$ & $0.94 \pm 0.06$ & $1.72 \pm 0.17$ \\
\hline 8 & GFDL-CM3 & $-0.09 \pm 0.07$ & $0.86 \pm 0.07$ & $-0.10 \pm 0.08$ \\
\hline 9 & GFDL-ESM2G & $0.83 \pm 0.09$ & $1.23 \pm 0.09$ & $0.67 \pm 0.09$ \\
\hline 10 & GFDL-ESM2M & $1.26 \pm 0.11$ & $0.84 \pm 0.06$ & $1.51 \pm 0.17$ \\
\hline 11 & GISS-EH & $0.09 \pm 0.06$ & $0.75 \pm 0.05$ & $0.12 \pm 0.08$ \\
\hline 12 & HADGEM2 & $1.06 \pm 0.10$ & $0.81 \pm 0.06$ & $1.31 \pm 0.16$ \\
\hline 13 & INMCM4 & $0.38 \pm 0.07$ & $0.63 \pm 0.04$ & $0.60 \pm 0.12$ \\
\hline 14 & IPSL-CM5-LR & $2.09 \pm 0.16$ & $1.30 \pm 0.09$ & $1.61 \pm 0.17$ \\
\hline 15 & IPSL-CM5-MR & $1.83 \pm 0.14$ & $1.20 \pm 0.08$ & $1.53 \pm 0.16$ \\
\hline 16 & MIROC-ESM & $0.40 \pm 0.06$ & $0.75 \pm 0.05$ & $0.53 \pm 0.09$ \\
\hline 17 & MIROC5 & $0.27 \pm 0.06$ & $0.63 \pm 0.05$ & $0.42 \pm 0.10$ \\
\hline 18 & MPI-ESM-LR & $1.70 \pm 0.13$ & $1.09 \pm 0.08$ & $1.57 \pm 0.16$ \\
\hline 19 & MPI-ESM-MR & $1.33 \pm 0.11$ & $1.10 \pm 0.08$ & $1.21 \pm 0.13$ \\
\hline 20 & MRI-CGCM3 & $0.42 \pm 0.05$ & $0.30 \pm 0.02$ & $1.38 \pm 0.19$ \\
\hline 21 & NCC-NORESM1 & $0.88 \pm 0.09$ & $0.79 \pm 0.06$ & $1.11 \pm 0.13$ \\
\hline \multirow[t]{3}{*}{22} & NCC-NORESM1-ME & $1.04 \pm 0.10$ & $0.83 \pm 0.06$ & $1.25 \pm 0.15$ \\
\hline & MME mean & $1.01 \pm 0.12$ & $0.90 \pm 0.09$ & $1.18 \pm 0.13$ \\
\hline & MME std dev & 0.61 & 0.30 & 0.79 \\
\hline
\end{tabular}

Multi model ensemble (MME) mean and multi model standard deviation are also indicated

\section{Attribution of long-term SST changes in the Kuroshio region}

\subsection{Observed features and reproducibility in MIROC5.2}

Figure 2a, b illustrate the time series of observed SST anomalies averaged in the KR and averaged globally over 1951-2010 (red curves), respectively. While global-mean SST increased monotonically during this period, this was not the case for the regional SST anomaly in the KR. SST decreased from the 1950s to 1980 s and then proceeded to increase, leading to a positive trend for 60 years. We examined whether the observed long-term change in SST in the $\mathrm{KR}$ was reproduced in the model. Figure $2 \mathrm{a}$ also presents the time series of the simulated SST anomaly in the KR in HIST (blue curve). The observed time series were within a 95\% confidence interval in HIST. The ensemble-mean SST anomaly also show multidecadal SST changes in the KR that are very similar to observations. This suggests that the multidecadal SST change as well as the long-term trend in the KR reflects a response to external forcing.
Figure 2c presents the annual-mean SST trend ratio in the KR to the global-mean in each period (1951-2010, 1961-2010, 1971-2010, and 1981-2010). The global-mean SST trends were roughly the same in all periods. This means the varying ratio of the SST trends (small for long term and large for short-term), was caused by a difference in the trend for the KR. Although the SST trend in the KR for 1951-2010 was slightly smaller than the global-mean (the ratio less than unity), the SST trend in the KR was larger than the global-mean in all other periods. There was a seasonality in the SST in the KR, showing that the SST increases during the late twentieth century are larger in winter than in summer (Fig. 2d). The SST trend ratio between the KR and the global-mean and its seasonality were well reproduced in the ensemble mean of HIST (blue curves in Fig. 2c, d). This supports our hypothesis that the multidecadal SST changes in observations arise from the externally forced component, not from internal variability.

Each HIST ensemble member consists of a combination of a forced component (i.e., signal) and internal variability inherent to the climate system (i.e., noise). To quantify the extent to which the forced component was 
(a)

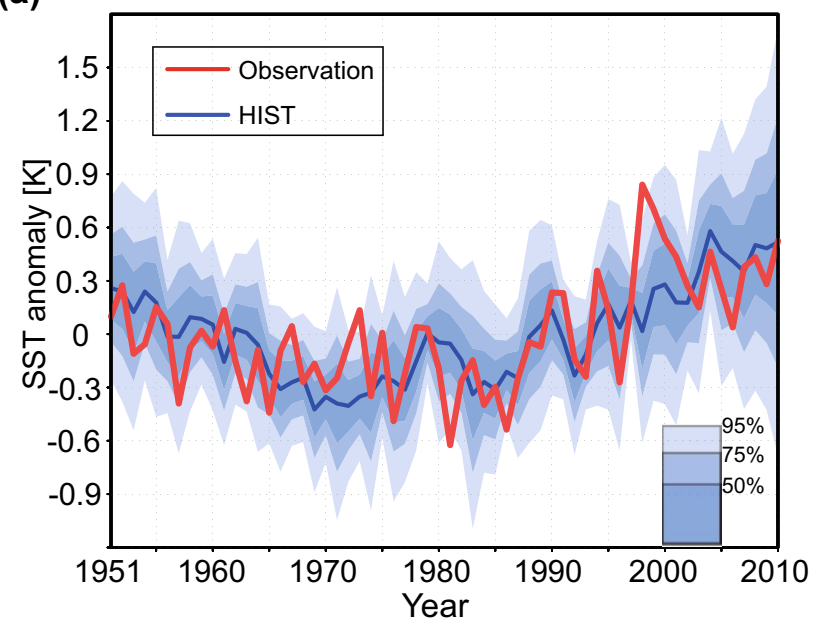

(c)

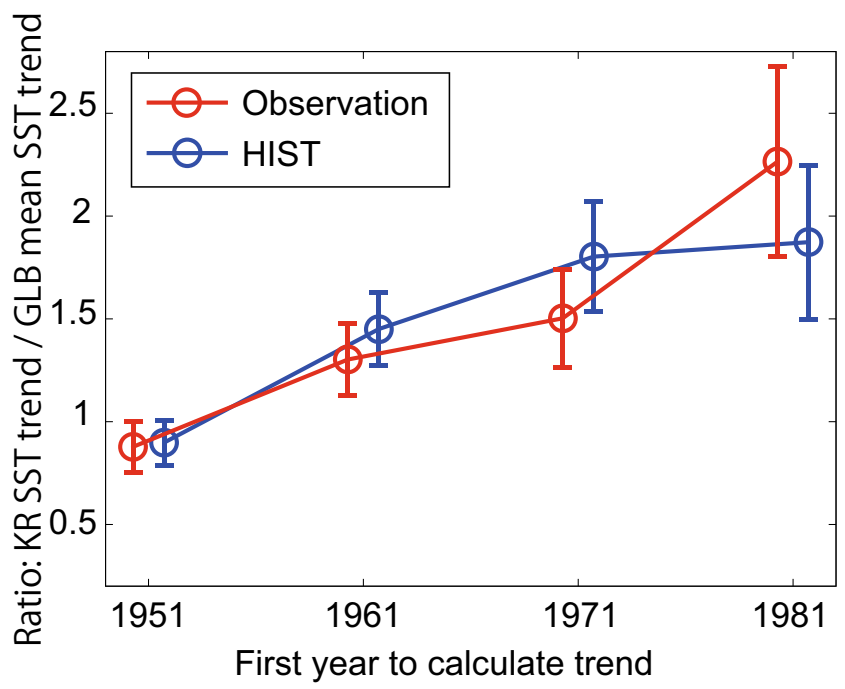

Fig. 2 a, b Time series of annual-mean sea surface temperature (SST) averaged in the Kuroshio region (KR) and the global ocean, respectively. The observed SST is shown in red and the simulated SST from the HIST ensemble mean is presented in blue, a shade indicating the 50,75 , and $95 \%$ confidence level. $\mathbf{c}$ The ratio of the annual-mean SST trend in the KR to the global-mean SST trend for different time win-

dominant in HIST, we calculated the signal-to-noise (SN) ratio. Here the signal is defined by the ensemble mean and noise was represented by subtracting the ensemble mean from individual members (Sect. 2.5). The SN ratio is defined as $\left(\sigma_{S} /\left(\sigma_{S}+\sigma_{N}\right)\right), \sigma_{S}$ is one standard deviation of signal calculated using the ensemble-mean time series for 60 years; and $\sigma_{N}$ is one standard deviation of noise calculated using deviations from the ensemble mean in 10 members (600 years in total). Table 3 presents the SN ratio of annual-mean SST calculated for each experiment. The

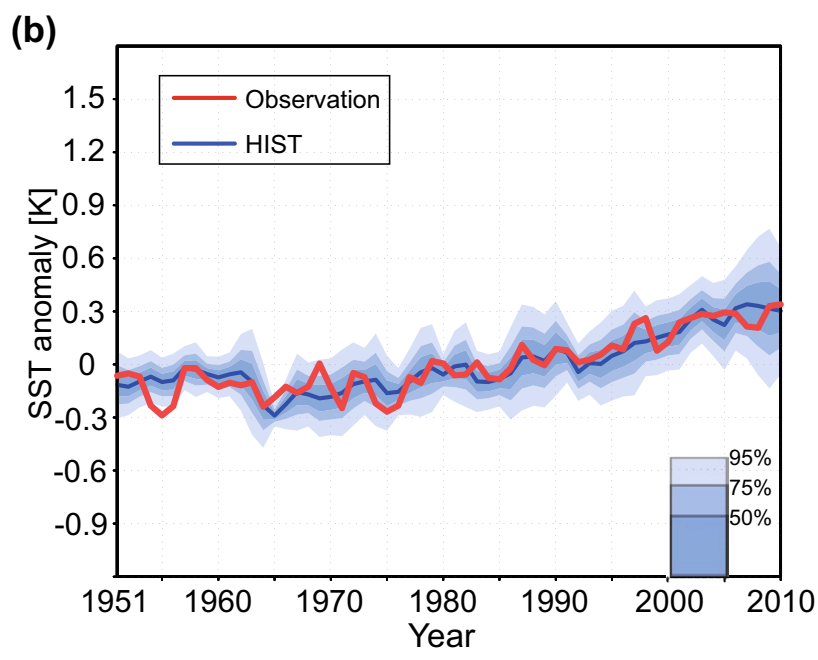

(d)

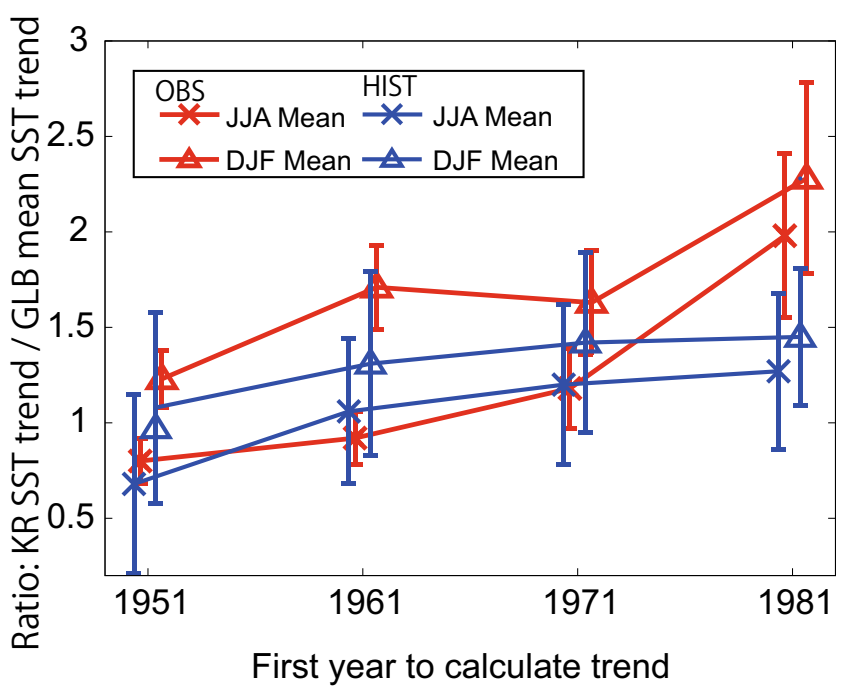

dows from observations (red) and HIST (blue). The end year for the trend was fixed at 2010, and the start year is indicated by the horizontal axis. The vertical error bar indicates $5-95 \%$ confidence interval of trends in observation and each experiment based on residual variance. d As in (c), but for JJA (X marks) and DJF (triangles)

SN ratio for the KR SST was 27\% in HIST, which is only slightly larger than the global mean of $23.6 \%$. However, the $\mathrm{SN}$ ratio using the 10-year low-pass filtered anomalies increase to $48 \%$ for the KR SST; this is larger than the global mean of $40.4 \%$. This indicates that half the decadal SST changes in the KR can be attributed to responses to external forcing in HIST. This large impact of the external forcing on SST in the KR is remarkable considering the possible influence of the Pacific Decadal Oscillation (PDO) to the SST variability in this region. 
Table 3 The signal-to-noise (SN) ratio of the Kuroshio region (KR) sea surface temperature (SST) in each experiment

\begin{tabular}{lll}
\hline & KR $(\%)$ & Global-mean $(\%)$ \\
\hline HIST & $27.0(48.0)$ & $23.6(40.4)$ \\
SO2CONST & $30.6(56.1)$ & $27.2(48.3)$ \\
AERO & $21.8(40.0)$ & $19.1(12.2)$ \\
MIROC6 historical run & $13.9(31.6)$ & $12.8(29.7)$ \\
\hline
\end{tabular}

The signal was defined by the ensemble mean and noise was represented by subtracting the ensemble mean from individual members (Sect. 2.5). The $\mathrm{SN}$ ratio was calculated as $\left(\sigma_{S} /\left(\sigma_{S}+\sigma_{N}\right)\right)$, where $\sigma_{S}$ is one standard deviation of signal and $\sigma_{N}$ is one standard deviation of noise. We used the results of SST for 1951-2010. The SN ratio was calculated using the 10-year low-pass filtered SST as indicated in brackets. 5-95\% confidence interval of trends of each model and MME are based on residual variance

\subsection{Relative contributions of greenhouse gasses and aerosol forcing}

In Sect. 3.1, we illustrated multidecadal SST changes in the KR during the late twentieth century, and suggested that they were partly caused by radiative forcing. In this section, we attribute the forced component to different radiative forcing agents, specifically GHGs and sulfate aerosols. Figure 3 a presents a time series of SST anomaly in the KR in HIST (blue curve) and SO2CONST (green curve). The figure shows that the KR SST increases monotonically in SO2CONST. As the impact of time varying radiative forcing due to sulfate aerosols was excluded in SO2CONST, the multidecadal SST change identified in HIST (and possibly in observations), was primarily driven by sulfate aerosols. We evaluated the SST trends in SO2CONST to verify whether the SST increase in the KR was also larger than the global-mean in this ensemble. The ratio of SST trends in the KR to the global-mean in each period in SO2CONST was calculated in a similar manner to Fig. 2c. These ratios were $1.44 \pm 0.23$ for $1951-2010$, $1.39 \pm 0.21$ for $1961-20101.45 \pm 0.4$ for $1971-2010$, and $1.21 \pm 0.64$ for $1981-2010$. The ratio was greater than unity and similar in most periods. These results suggest that the mechanism enhancing ocean surface warming is GHG forcing.

As the SST increase post-1980 is the most conspicuous in the KR (Fig. 2a), the relative contribution of GHGs and sulfate aerosols forcing the SST trend for 1981-2010 was assessed. This was done using a combined analysis of HIST and SO2CONST in which the response GHGs was found to be dominant (see Sect. 2.5). We compared the SST trends in COBE-SST, HIST, SO2CONST, and AERO (see Sect. 2.5 for the definition) in Fig. 3b. Over this period, SST trends due to sulfate aerosols were comparable to those due to GHGs, although the uncertainty in the former was large. In general, sulfate aerosols cool the surface of the Earth, but SST trends in the KR caused by sulfate aerosols vary depending on the period. For example, a weakening of the cooling effect by sulfate aerosols due to reduced emissions, could result in a positive trend. Section 4.3 provides further discussion on SST change in the KR forced by sulfate aerosols. (a)

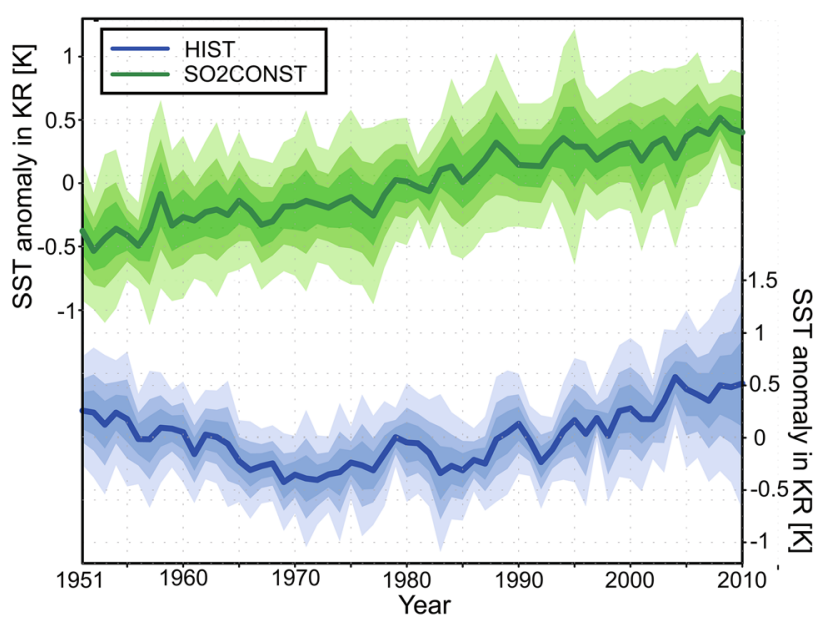

Fig. 3 a Time series of the annual-mean sea surface temperature (SST) anomalies in the Kuroshio region (KR) obtained from HIST (blue, replicated from Fig. 2a) and SO2CONST (green). The other convention follows Fig. 2a. b SST trends in the KR for 1981-2010: (b)

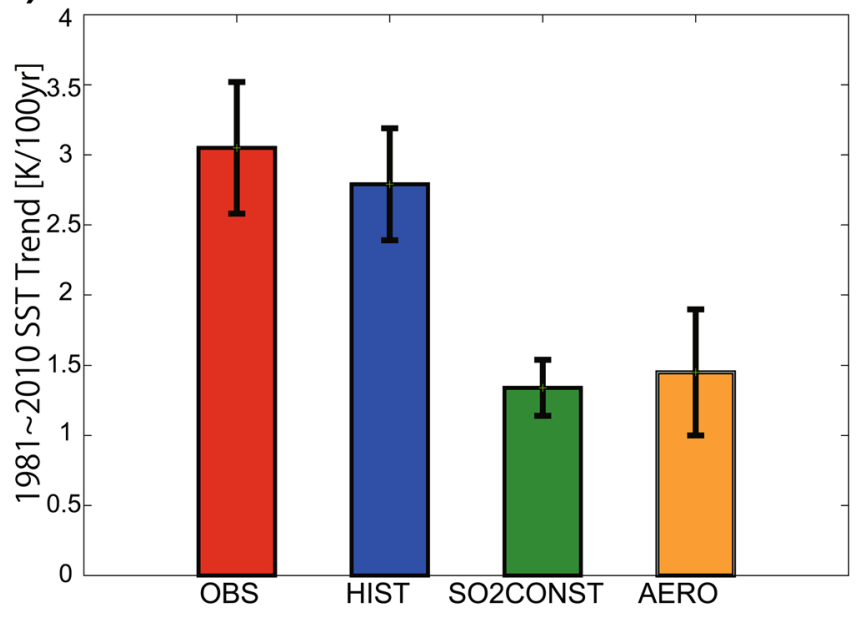

observation (red), HIST (blue), SO2CONST (green), and AERO (orange, see text for the definition). The vertical error bar indicates the 5-95\% confidence interval of trends in observation and each experiment based on residual variance 


\section{Mechanisms of SST changes in the Kuroshio region}

In Sect. 3, we described features of SST trends in the KR and the role of external forcing in the simulated SST trend. However, the SST trend depends on the time period chosen (cf. Fig. 2c). As such, trend analysis alone is not enough to reveal the mechanisms underpinning the increase of SST in the KR. In this section, we analyze the low-pass filtered anomalies derived from HIST to clarify the mechanisms influencing multidecadal SST variability, including a linear trend, generated in the KR. To determine the horizontal patterns in low-frequency SST anomalies associated with SST variability in the KR, we obtained a regression of low-pass filtered SST anomalies against the low-pass filtered SST time series in the KR in HIST for 1951-2010. As in the previous section, we used the ensemble-mean anomalies to isolate the forced component while ensemble deviations were used to identify internal variability.

Figure 4 presents global maps of regression patterns in low-frequency SST anomalies. The time period for the regression was 1951-2010, but the 2011-2015 period was discarded when low-pass filtered data was used. In the KR, there is little difference between the forced component and internal variability (Fig. 4b, d). However, the regression patterns were found to be different at a larger scale (Fig. 4a, c). The spatial pattern of internal variability (Fig. 4c), shows that the positive SST anomaly in the KR extends to the northwestern Pacific surrounded by negative anomalies. (a)

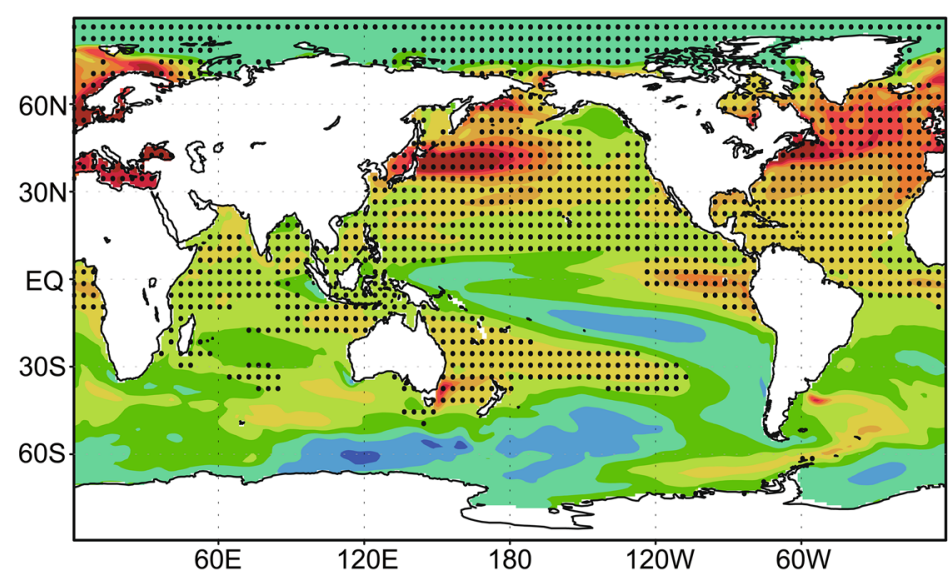

(c)

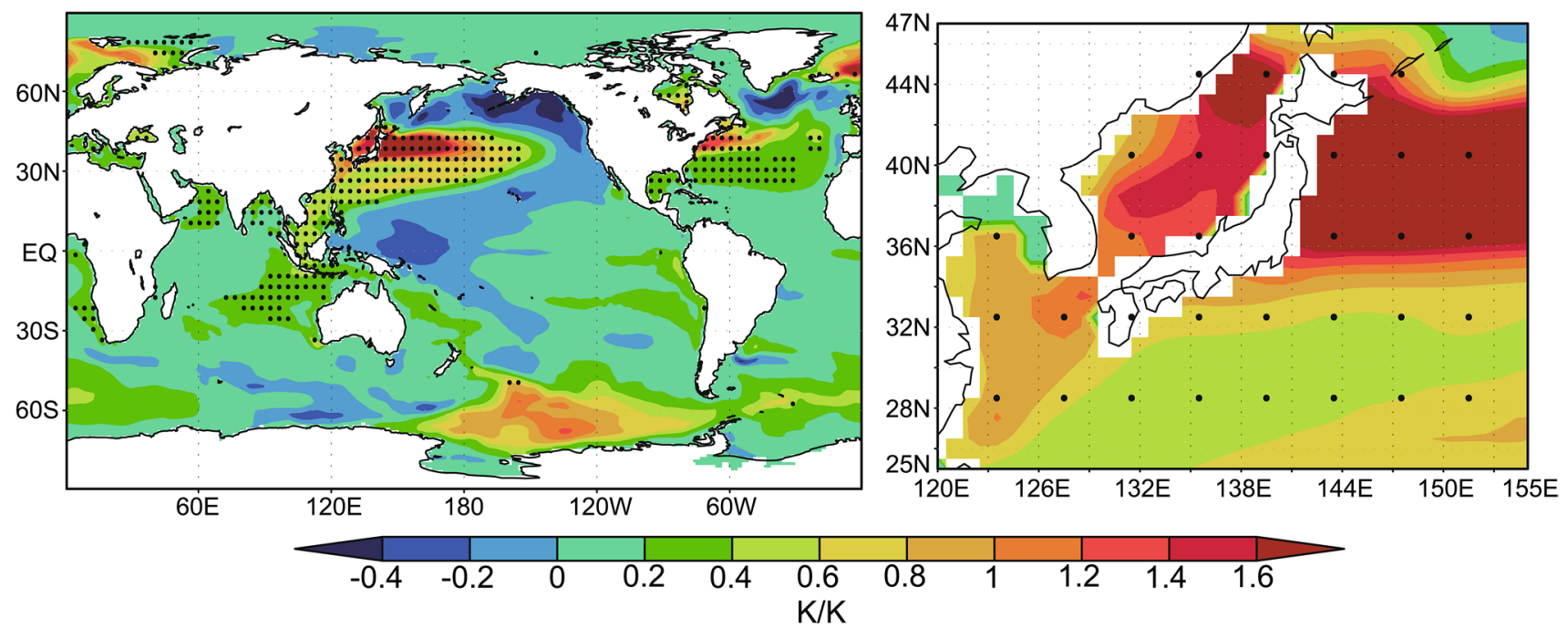

(b)

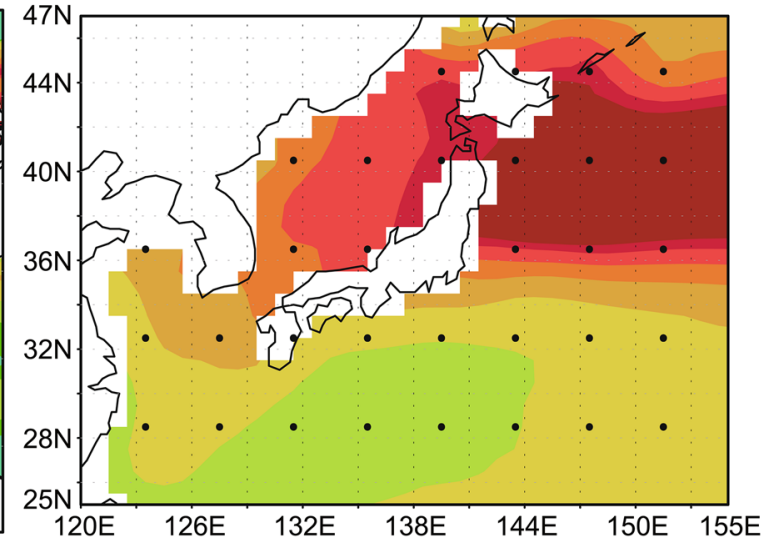

(d)
Fig. 4 a Annual-mean sea surface temperature (SST) anomalies regressed on the SST time series in the Kuroshio region (KR) and b the enlarged view of the KR. The regression was calculated using the 10-year low-pass filtered anomalies from the ensemble mean. The dots indicate the regressed anomaly that was statistically significant at the $95 \%$ confidence level. c, d As in (a, b), but for the regression based on the ensemble deviations 
This is reminiscent of the negative phase of the PDO. The spatial pattern of the forced component also includes positive SST anomalies in the northwestern Pacific, but negative SST anomalies were absent in the North Pacific. Additionally, large positive SST anomalies were found in the North Atlantic. This suggests that the mechanism of multidecadal SST variability in response to radiative forcing was different from that for internal variability. In Sect. 4.1, we examine processes that may drive the forced SST anomaly in the KR.

\subsection{Mixed-layer heat budgets}

To identify the source of ocean surface heating in the KR, we calculated heat budgets for the ocean mixed layer temperature $\left(T_{m}\right)$, assuming mixing in the layer leading to SST could be approximated by $T_{m}$ :

$\frac{\partial T_{m}}{\partial t}=E+\frac{Q_{n e t}}{\rho C_{p} H}$,

where $Q_{n e t}$ denotes the net heat flux at the ocean surface, $\rho$ is sea water density; $C_{p}$ is the specific heat, $H$ is the mixed layer depth (MLD); and $E$ represents the sum of ocean dynamical terms induced by geostrophic and Ekman flows. By linearizing (1) with respect to climatology denoted by overbars, we obtain the anomaly equation in which the prime indicates low-frequency anomalies:

$\frac{\partial T^{\prime}{ }_{m}}{\partial t}=\frac{Q_{n e t}^{\prime}}{\rho C_{p} \bar{H}}-\frac{\overline{Q_{n e t}} H^{\prime}}{\rho C_{p} \bar{H}^{2}}+E^{\prime}$

We calculated each term in (2) for individual ensemble members. We ignored the cross terms in the ensemble members assuming that ensemble deviations were not correlated with each other. The left-hand side of (2) indicates the anomalous temperature tendency in the mixed layer, to which three source terms appear on the right-hand side. The first term indicates the net surface heating anomaly, the second term denotes anomalous heat due to changes in the MLD, and the third term represents the bulk effect of ocean dynamics, estimated as a residual of the budget equation. Following (2), we evaluated the contribution of each term to the SST anomaly in the KR.

Figure $5 \mathrm{a}-\mathrm{c}$ present the regression of each term against the filtered ensemble-mean time series of SST averaged over the KR. Based on a comparison with Fig. 4b, it is likely that the positive SST anomaly in the north-eastern KR was induced by ocean dynamics, whereas the net surface flux anomaly acts to warm the entire region except for the northeastern KR (Fig. 5a, c). Unlike these two terms, anomalous heat due to changes in the MLD act to diminish the SST anomaly (Fig. 5b). This occurs with a shallowing MLD, effectively cooling the mixed layer when coupled with the climatological net heat flux from the ocean to the atmosphere (upward in the KR). The mixed layer becomes shallow in response to a weakening of the Kuroshio current, as discussed in Sect. 4.2.

The contribution to the SST anomaly in the KR was estimated by averaging the budget terms change, over the region (Fig. 5d). As expected, the anomalous heating due to ocean dynamics and the net surface flux were equally important for warming the mixed layer in the KR. The net surface flux can be further decomposed into four components; longwave radiation (LR), shortwave radiation (SR), sensible heat flux $\left(Q_{s}\right)$ and latent heat flux $\left(Q_{l}\right)$, (see Fig. 5d). It was found that heating due to anomalous sensible heat flux was the largest, followed by the heating due to longwave radiation. In the forced component, the longwave heating would have occurred due to GHGs and the water vapor feedback which does not necessarily favor warming the KR. This was confirmed by the regressed heating rate by longwave radiation which was slightly smaller than global mean $\left(0.24 \mathrm{~K}_{\text {year }}{ }^{-1} \mathrm{~K}^{-1}\right)$. Therefore, the anomalous sensible heat flux represents an atmospheric driving of ocean surface warming in the KR.

Sensible heat flux is proportional to the difference between SST and the near-surface atmospheric temperature. Thus, the positive contribution of the anomalous sensible heat flux to the SST increase in the KR suggests that the lower troposphere warms more than the SST when the KR SST shows a positive anomaly. Indeed, the regression of low-frequency temperature anomalies at $850 \mathrm{hPa}$ (T850) against the ensemble-mean SST time series in the KR shows a large positive anomaly over the northwestern Pacific to the north of the KR (Fig. 6a). Climatologically, SST in the $\mathrm{KR}$ is cooled by cold air advection from the continent due to the winter Asian monsoon. In the twentieth century, the Eurasian continent experienced a large temperature increase. As such, it is possible that the warming anomaly in T850 in the KR (Fig. 6a), was associated with a large warming over the continent through horizontal advection, as mentioned in Sect. 1.

To determine whether the positive T850 anomaly in the KR was caused by horizontal temperature advection associated with the continental warming, we quantified the regression of horizontal temperature advection at $850 \mathrm{hPa}$, corresponding to the T850 anomaly pattern (Fig. 6b). The positive advection anomaly was found over the eastern edge of the Eurasian continent and the northwestern Pacific. This anomaly in horizontal advection can be decomposed into two terms; $v^{\prime} \cdot \nabla \bar{T}+\bar{v} \cdot \nabla T^{\prime}$. The first term was the advection by anomalous circulation (called the dynamic component), and the second term represents the advection of the temperature anomaly by the mean winds (called the thermodynamic component). The regression maps for the above two terms illustrate that the positive temperature advection 
(a)

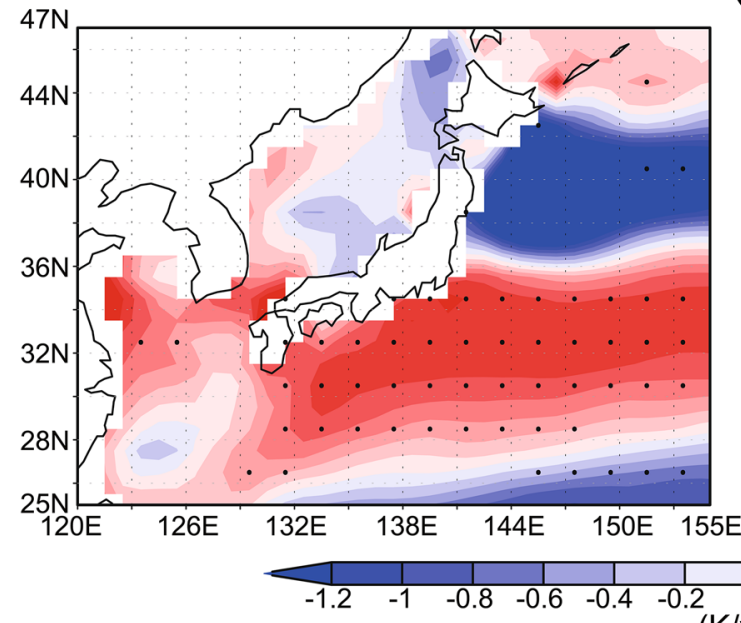

(c)

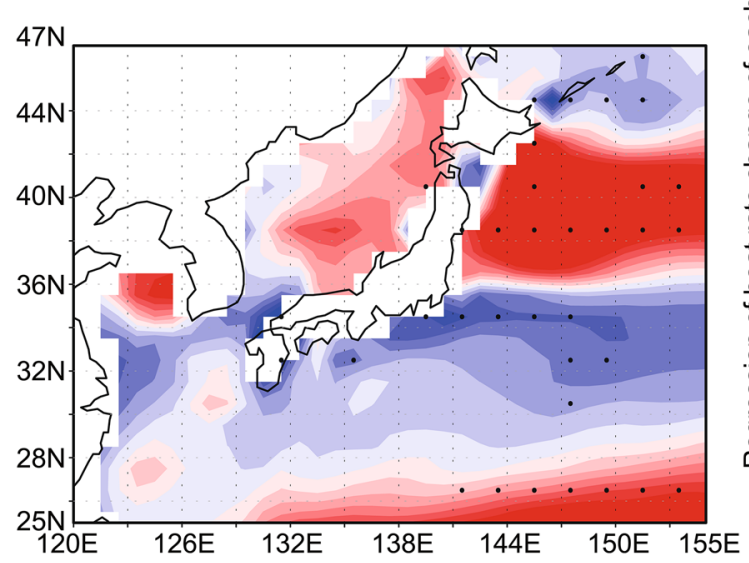

Fig. 5 a-c Spatial patterns of mixed layer heat budgets regressed on to the sea surface temperature (SST) anomaly in the Kuroshio region (KR): Contributions by the net surface heat flux, anomalous mixedlayer depth (MLD), and ocean dynamics. All the values were calculated using the 10-year low-pass filtered ensemble-mean anomalies in

anomaly was caused by changes in atmospheric circulation (Fig. 6c, d), not by the increase in temperature over the Eurasian continent.

The low-frequency geopotential height anomalies at $500 \mathrm{hPa}(\mathrm{Z} 500)$ regressed on the ensemble-mean SST time series in the KR, as shown in Fig. 7a. There exists a large high-pressure anomaly over the North Pacific, indicating an anomalous anticyclonic circulation, transporting warm air into the western side of the high-pressure anomaly and resulting in a positive horizontal advection anomaly. The high-pressure anomaly was also found in the regression of sea level pressure (SLP; Fig. 7b). This analysis indicates that the forced high-pressure anomaly has led to heating in the lower troposphere, causing the KR SST to increase via suppression of the sensible heat flux from the ocean surface. (b)

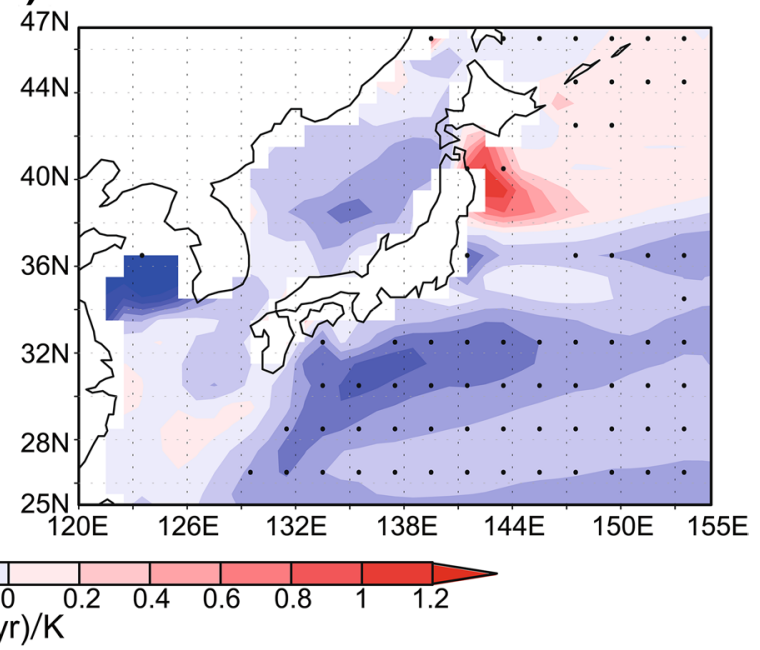

(d)

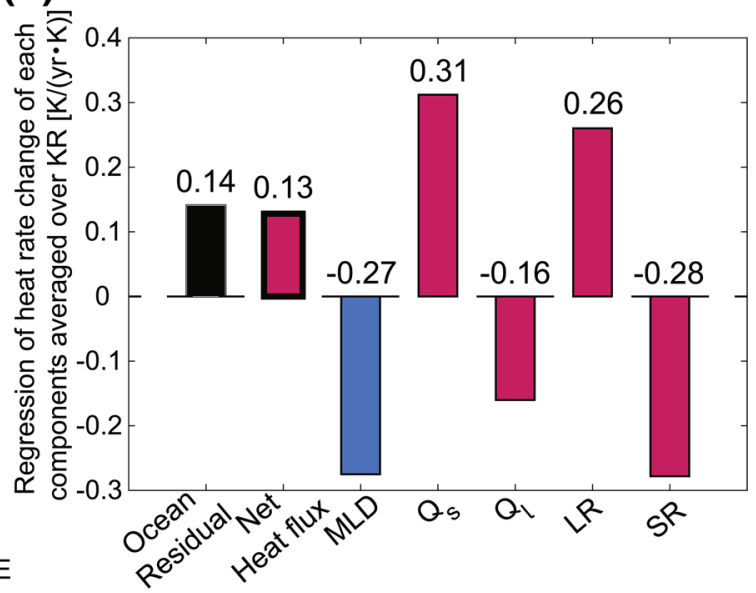

HIST. d Regressed budget terms averaged in the KR. Right four bars indicate the decomposition of the net surface heat flux into each component; longwave radiation (LR), shortwave radiation (SR), sensible heat flux $\left(Q_{s}\right)$ and latent heat flux $\left(Q_{l}\right)$

The sensible heat flux anomaly can also be generated by anomalous wind speed at the surface. Indeed, surface westerly winds weaken over the KR in association with the highpressure anomaly found in Fig. 7. However, the regressed change in the wind speed was not statistically significant for the KR. Therefore, we may conclude that the temperature advection in the lower troposphere induced by the high-pressure anomaly was the primary driver of the upward sensible heat flux anomaly over the KR.

\subsection{Changes in ocean circulation}

In this section, we discuss the oceanic circulation change that may potentially cause large SST increases in the north-eastern KR in HIST, as shown in Fig. 5c. Figure 8a 
(a)

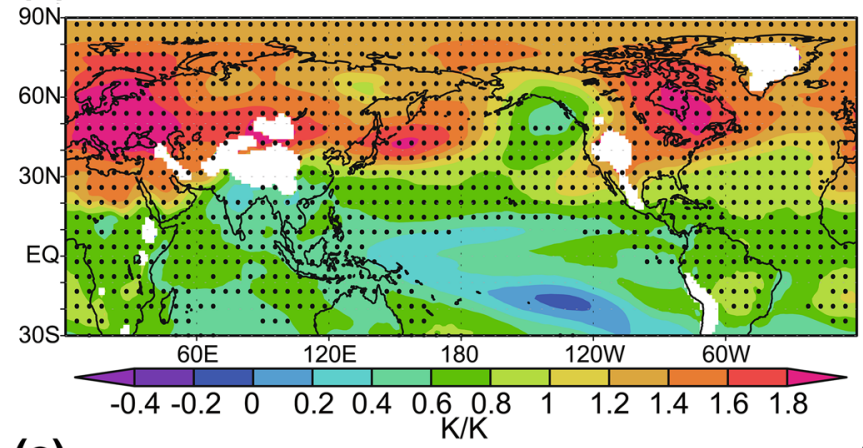

(c)

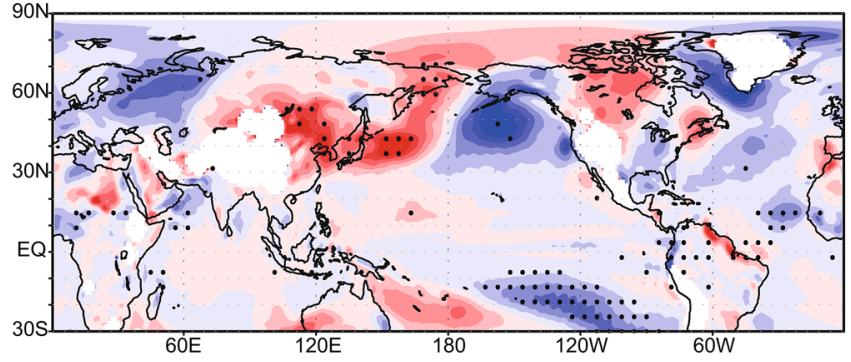

Fig. 6 Spatial patterns of annual-mean anomalies in a T850, b horizontal temperature advection at $850 \mathrm{hPa}, \mathbf{c}, \mathbf{d}$ dynamic and thermodynamic components of (b), regressed onto the sea surface temperature (SST) time series in the Kuroshio region (KR). All the values are cal-

presents a climatology of SST and oceanic currents averaged in the mixed layer in HIST. The Kuroshio currents were observed along Japan and leave the shore at around $36^{\circ} \mathrm{N}$ as in observations. However, ocean eddies are not resolved in MIROC5.2. There exists a south-westward current at $42^{\circ}-47^{\circ} \mathrm{N}$ and $145^{\circ}-155^{\circ} \mathrm{E}$, transporting cold water from the north. Its velocity was much slower than that observed in the Oyashio current. Figure $8 \mathrm{~b}$ presents a regression of low-frequency anomalies in SST (color) and ocean horizontal velocity (vector) against ensemble-mean time series of SST in the KR in HIST. A significant positive SST anomaly was found for the region $37^{\circ}-44^{\circ} \mathrm{N}, 141^{\circ}-155^{\circ} \mathrm{E}$, where a north-eastward current was strengthened bringing warm water flow from the south. This increase in oceanic velocity occurs to the north of axis of the mean Kuroshio current (Fig. 8a). South of $32^{\circ} \mathrm{N}$, the north-eastward Kuroshio current was weakened. This indicates a poleward migration of Kuroshio currents against radiative forcing, consistent with Saenko et al. (2005) and Wu et al. (2012).

As the western boundary current was formed via a propagation of long Rossby waves excited by wind stress curl over the basin, the changes in stress curl over the North Pacific were expected to be consistent with the change in the Kuroshio current. The regression map of low-frequency wind stresses (vector) and their curl (color) against the ensemble-mean time series of SST in the KR in HIST shows an (b)

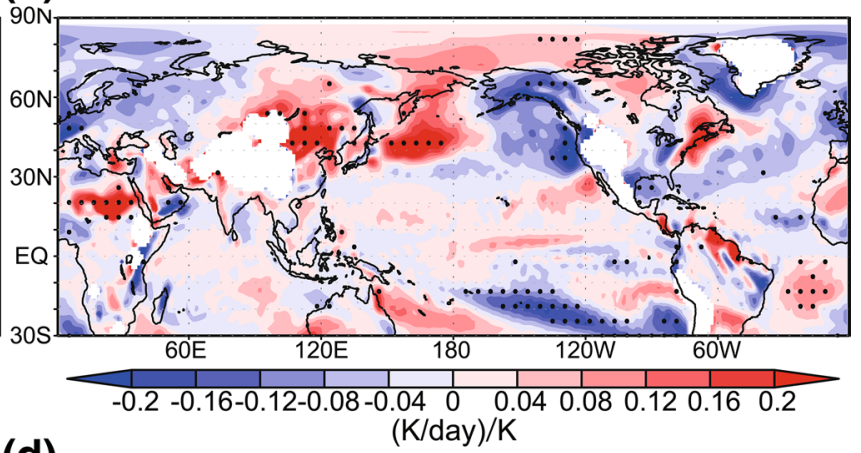

(d)

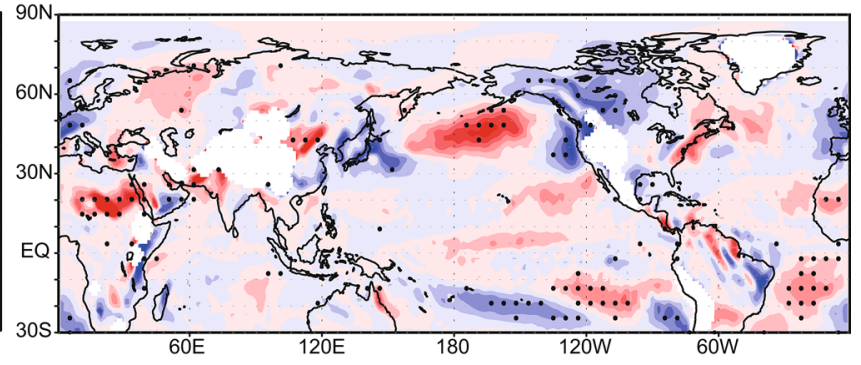

culated using the 10-year low-pass filtered ensemble-mean anomalies in HIST. The dots indicate the regressed anomaly that was statistically significant at the $95 \%$ confidence level

anticyclonic anomaly over the North Pacific (Fig. 8c). This anomaly would be a surface signature of high-pressure anomalies over the North Pacific (Fig. 7). It is also likely that the poleward migration of the Kuroshio current indicated in Fig. $8 \mathrm{~b}$ can be explained by the strengthening of negative stress curls at $30^{\circ}-37^{\circ} \mathrm{N}$. These results suggest that the high-pressure anomaly over the North Pacific affects the SST increase in the KR via atmospheric circulation and changing wind-driven ocean circulation.

\subsection{High-pressure response to greenhouse gasses and sulfate aerosols over the North Pacific}

In the above two sections, we presented two mechanisms of externally forced changes in SST in the KR identified in HIST. The first mechanism was a decrease in the upward sensible heat flux to the atmosphere and the second mechanism was a change in oceanic currents. In both mechanisms, the high-pressure anomaly over the North Pacific appears to play a crucial role. In this section, we attempt to reveal the differences between changes in the pressure field over the North Pacific forced by GHGs and those forced by sulfate aerosols in MIROC5.2 using the results of HIST, SO2CONST, and the AERO component (i.e., HIST minus SO2CONST). We essentially adapted a similar analysis with HIST to the results of SO2CONST and AERO. 


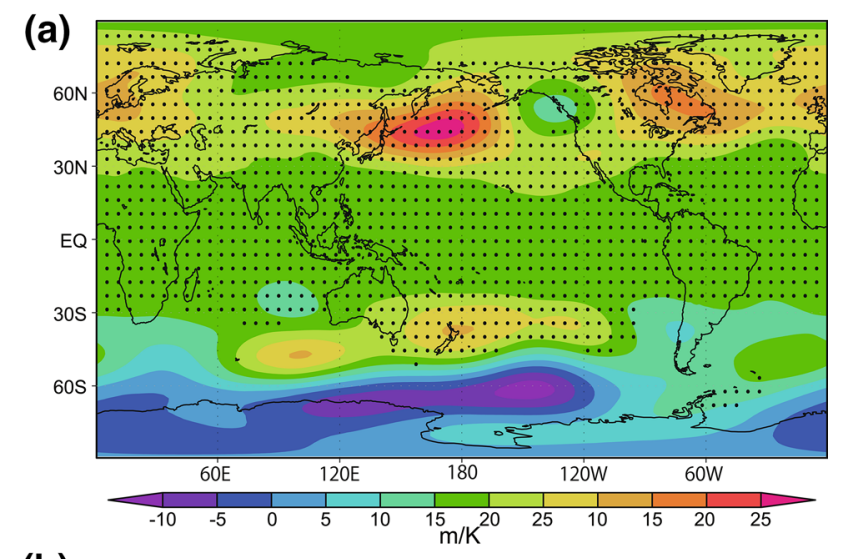

(b)

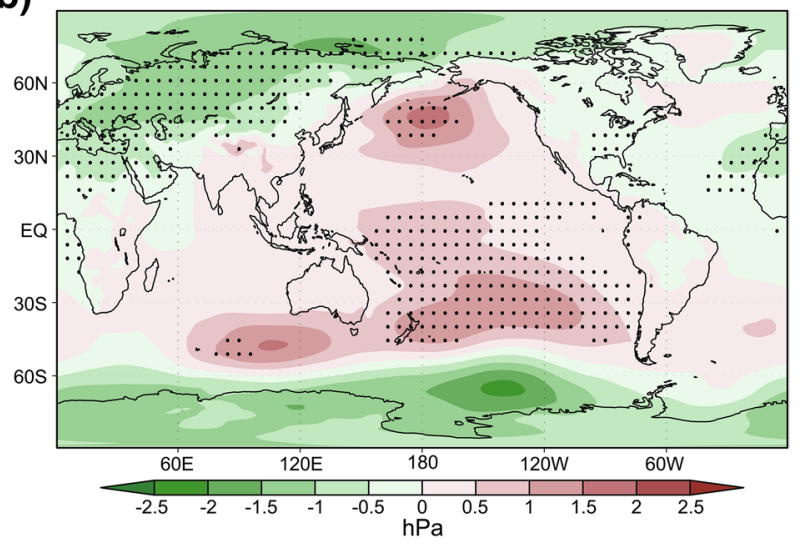

Fig. 7 As in Fig. 6a, but for the geopotential height at $500 \mathrm{hPa}$ (Z500, a) and sea level pressure (SLP, b)

$\mathrm{SN}$ ratio for the KR SST shows the SST in the KR in both SO2CONST and AERO was large enough to be detected and was larger than the global-mean (Table 3). Regression maps of the low-frequency SST anomaly against the ensemble-mean time series of SST in the KR in SO2CONST and AERO are depicted in Fig. 9a, b, respectively. Overall, these were similar but some key differences were present. In SO2CONST, statistically significant increases in SST were observed in ocean basins around the globe even in the Southern Hemisphere. This suggests that the GHG forcing has a global impact. In AERO, a large positive SST anomaly was confined to the north-western Pacific.

Figure 9c, d present regression maps of Z500 against ensemble-mean time series of SST for the KR in SO2CONST and AERO. A high pressure anomaly was found in both SO2CONST and AERO. The position of the high-pressure anomaly in AERO was more northwest than in SO2CONST, consistent with a slight difference in the location of the maximum SST anomaly.

This indicates that the high-pressure anomaly over the north Pacific emerges in association with the positive SST anomaly in the KR, irrespective of the type of radiation forcing. However, the time series of SST anomaly in the
KR in HIST and SO2CONST show a clear difference in the magnitude of multidecadal changes (Fig. 3a). We investigated the cause of this difference. Figure $10 a-c$ presents the time series of the 10-year low-pass filtered Z500 anomaly over the North Pacific (i.e., $30^{\circ}-50^{\circ} \mathrm{N}, 140^{\circ} \mathrm{E}-150^{\circ} \mathrm{W}$; the area was determined according to the position of the highpressure anomaly in HIST in Fig. 7). Again, a multidecadal change was found in HIST (Fig. 10a) corresponding to the multidecadal SST change in the KR (Fig. 2a). Much of this multidecadal variability was found to be due to multidecadal pressure change in response to the sulfate aerosol forcing because it exists in AERO but not in SO2CONST (Fig. 10b, c).

\section{Validating physical mechanisms}

\subsection{Enhanced ocean surface warming in CMIP5 multi-models and a large ensemble simulation by MIROC6}

In previous sections, we found that the positive Z500 anomaly over the North Pacific plays a major role in giving rise to the positive SST anomaly in the KR in the ensemble-mean fields. The 10-member ensembles by MIROC5.2 were useful to detect such forced multidecadal variability, but the above results were based on a single model experiment. In this section, we analyze the CMIP5 multi-model ensemble (cf. Table 2) and the MIROC6 large ensemble historical simulation to identify whether these support the close relationship between the high-pressure anomaly over the North Pacific and the SST anomalies in the KR.

Figure 11a presents a 10-year low-pass filtered time series of SST in the KR from COBE-SST (red curve) and the 22 historical and RCP4.5 runs (black curve for the ensemble mean). The multi-model ensemble (MME) mean, roughly reproduced observed long-term SST changes in the KR. The ensemble spread was clearly larger than that of HIST (Fig. 2a), because it reflects uncertainty due to internal variability and the different model biases. The observed SST changes in the KR were within a $95 \%$ confidence interval of the CMIP5 multi-models. Table 2 presents the values of SST trends for 1951-2010 in the KR and global-mean as well as their ratios. In 14 of 22 models, a larger increase occurred in the KR SST than the global-mean. The MME also exhibited an enhanced SST increase in the KR, although the standard deviation was large. To identify the relationship between the enhanced ocean surface warming in the KR and highpressure tendencies over the North Pacific, we calculated the linear trends of both quantities from 1951-2010 for each of the 22 GCMs. The results are shown in Fig. 11b, in which the SST trends in the KR and the Z500 trends over the North Pacific have been scaled with the global-mean trends for 
(a)

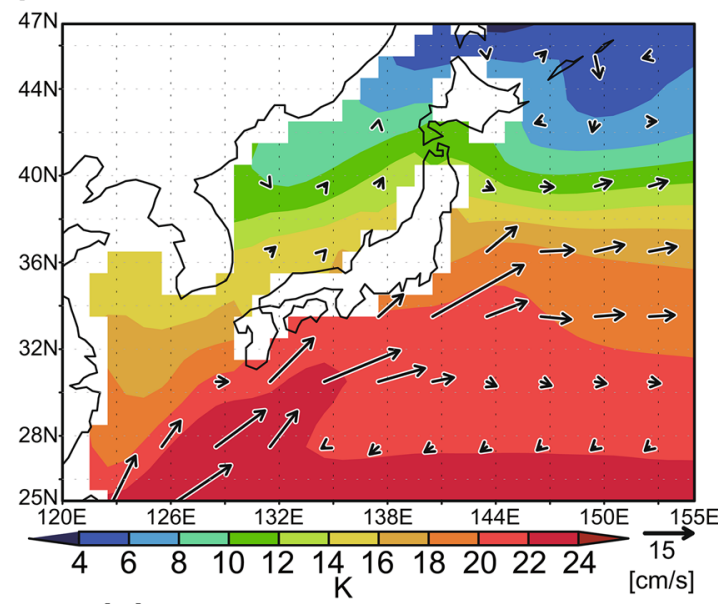

(b)

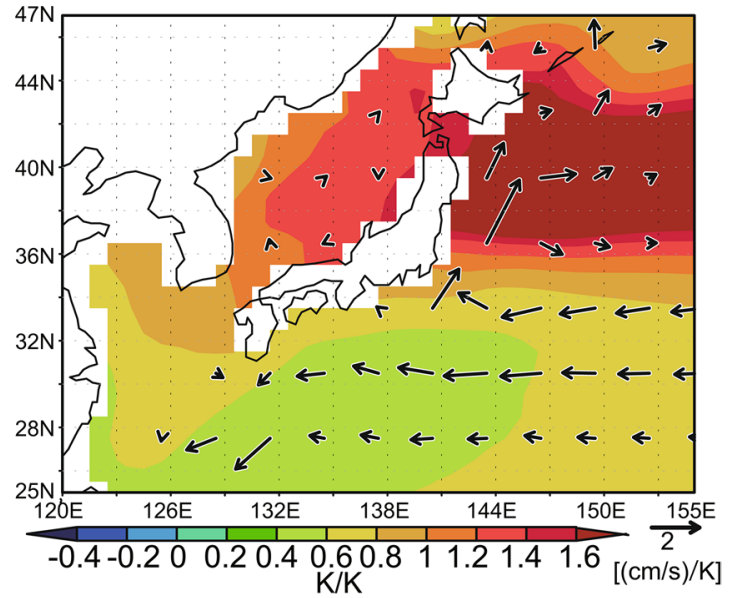

(c)

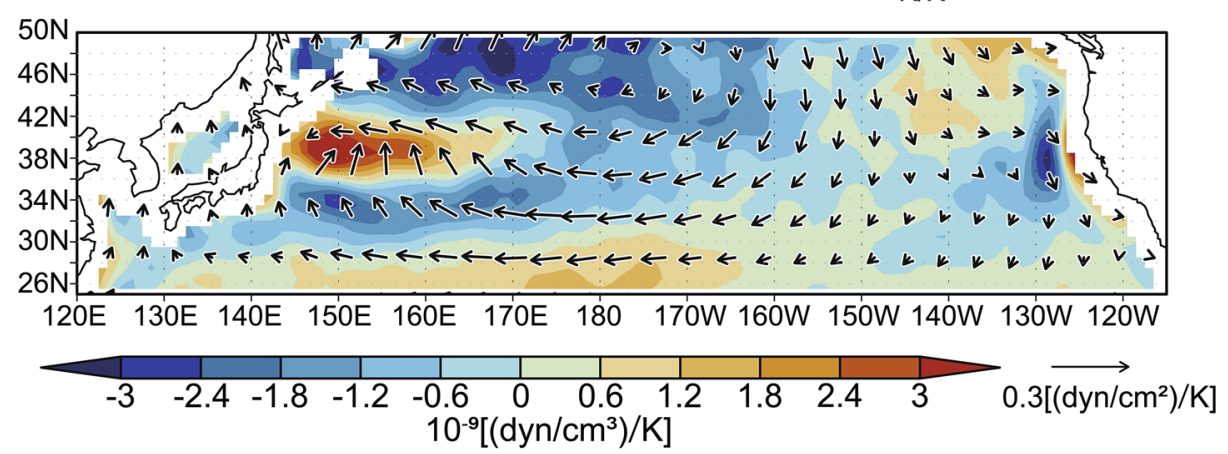

Fig. 8 a Climatological SST (shading) and ocean current velocity averaged in the mixed layer (arrows) in HIST. The climatology is based on the average for 1951-2010. b As in Fig. 6a, but for sea surface temperature (SST) (shading) and mixed-layer ocean currents (arrows). c As in Fig. 6a, but for wind stress curl (shading) and wind stresses (arrows)

external forcing when the contribution of internal variability was fully represented with a large ensemble.

The scatter plot between SST and Z500 trends for 1951-2010 show that they are positively correlated but the coefficient was smaller than the CMIP5 ensemble $(r=0.48$, Fig. 11d). Given that this low correlation arises from internal variability alone, the high correlation in the CMIP5 multi-models represent the difference in magnitude of the externally forced responses among models. These results suggest that the magnitude of the North Pacific Z500 trend is a controlling factor for long-term SST increase in the KR. This supports the mechanism identified from the MIROC5.2 ensembles.

\subsection{Observed changes}

Thus far, we have demonstrated the importance of tropospheric pressure changes over the North Pacific for enhanced ocean surface warming in the KR based on GCMs. In this section, we revisit this relationship in observations and reanalysis data. Figure 12a illustrates the observed SST trends from 1981 to 2010 . This period 
(a)

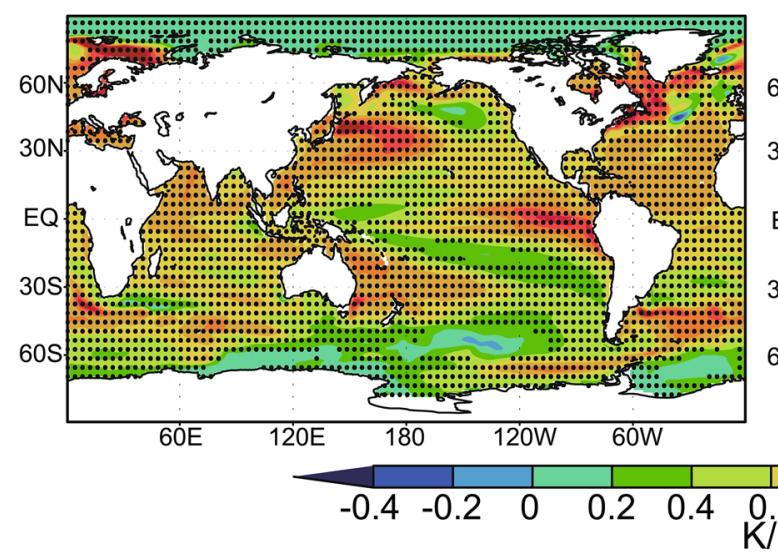

(b)

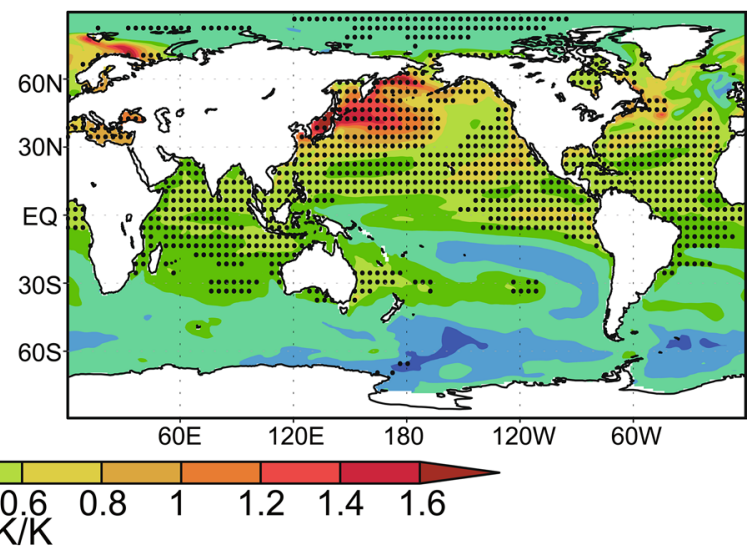

(c)

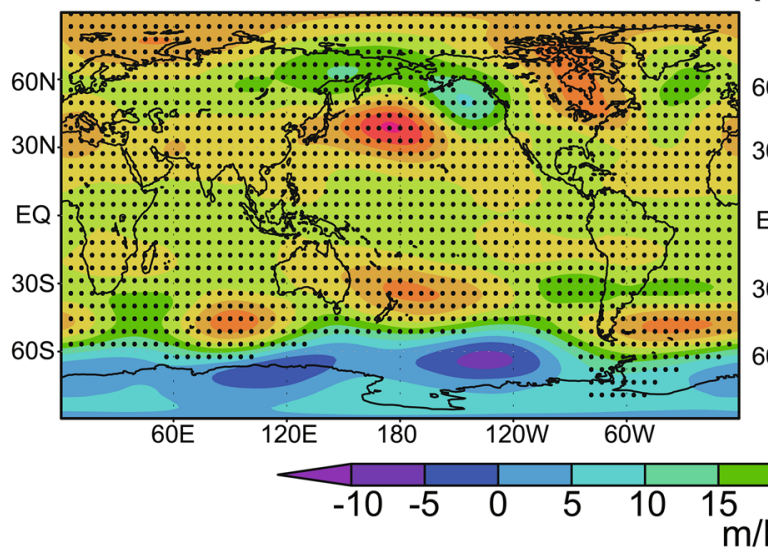

(d)

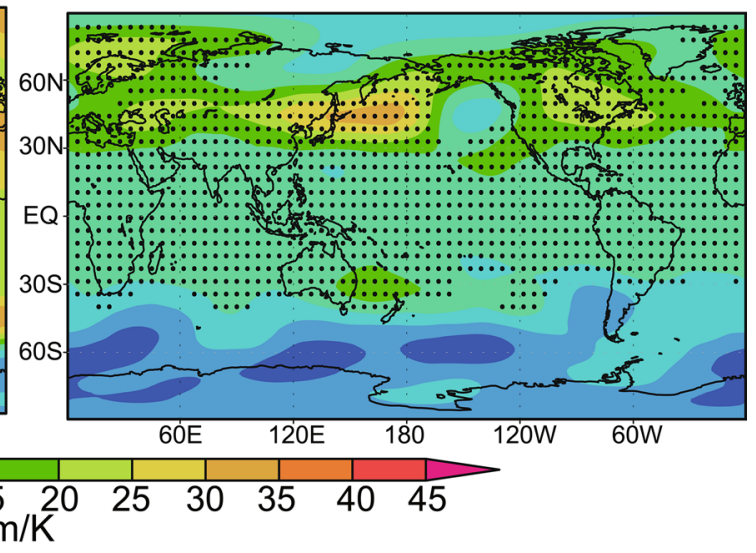

Fig. 9 a, b As in Fig. 4a, but from SO2CONST and AERO. c, d As per (a, b), but for Z500

was selected as the SST increases linearly in the KR, with a significantly large trend (Fig. 2c), even though the trend for this shorter period may be more affected by internal variability. In this period, the SST trend in the KR was 2.3 times larger than the global-mean (Fig. 2c), which may partly be attributed to the negative phase of PDO as seen in Fig. 12a.

The SST trend pattern from the HIST ensemble mean shows some similarity to observations, except it lacks the negative trends in the eastern basin of the tropical Pacific (Fig. 12b). Figure 12c depicts the trend of Z500 derived from the JRA-55 reanalysis for the same period. A significant high-pressure tendency was observed over the North Pacific and again this was reproduced by the HIST ensemble mean (Fig. 12d). It is not possible to eliminate the PDO-related trends from observations and reanalysis data, but the similarity with the ensemble mean suggests that the effect of internal variability, i.e., PDO, was not dominant. Additionally, the phase change of the PDO was partly forced by radiative forcing (Boo et al. 2015).

\section{Summary and discussion}

We investigated the mechanisms underpinning the large SST increases in the KR during the late twentieth century based on observational data and numerical experiments using MIROC5.2. Observed SST changes in the KR demonstrate a slight decrease since 1951 until around 1980 , but a subsequent rapid increase. Due to this nonmonotonic change in SST in the KR, the SST trend in the KR varies depending on the period. Nevertheless, for any time period, the SST trend in the KR was larger than the global-mean SST trend. The SST trend in the KR has a clear seasonality that shows a larger warming in winter than in summer. We showed that the external radiative forcing can account for one third to half of the multidecadal SST change in the KR based on MIROC 5.2 and MIROC 6 historical simulation. Using two sets of 10-member ensemble historical simulations by MIROC5.2 we found that GHGs and sulfate aerosols play an equally 
(a)

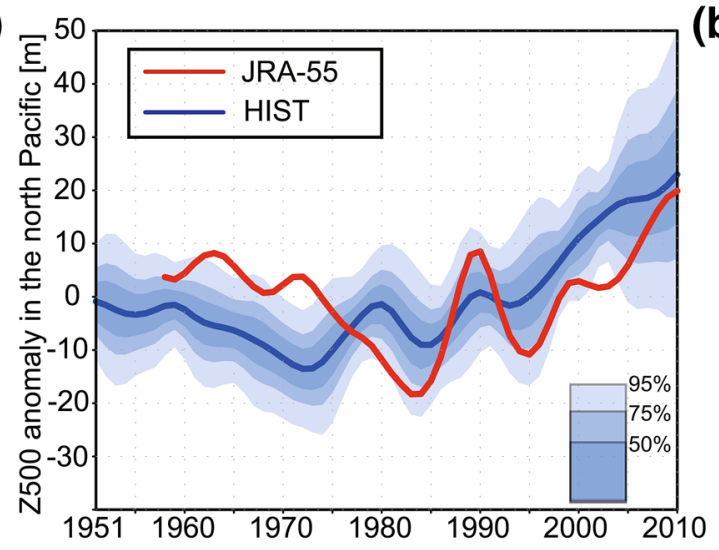

(b)

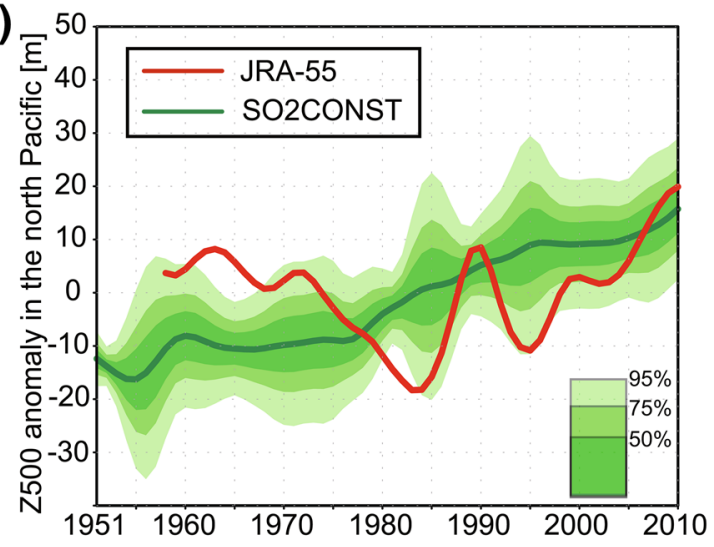

(c)

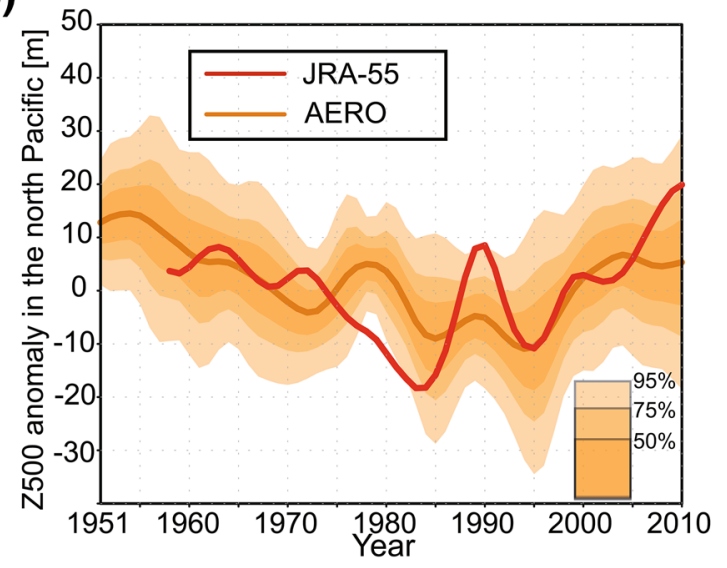

Fig. 10 a-c Time series of the 10-year low-pass filtered Z500 anomaly averaged over the North Pacific $\left(30^{\circ} \mathrm{N}-50 \mathrm{~N}, 140^{\circ} \mathrm{E}-150^{\circ} \mathrm{W}\right)$ from HIST, SO2CONST, and AERO, imposed on the time series from JRA-55 reanalysis. Other conventions follow Fig. 2a

important role. Namely, GHGs alone generate a monotonic SST increase in the KR larger than the global-mean SST increase. However, the multidecadal change was mainly driven by the sulfate aerosol forcing.

The mechanisms of distinctively large SST increases in the KR consist of two processes; increased sensible heating from the atmosphere caused by a large warming of the lower troposphere and the anomalous temperature advection in the ocean mixed layer associated with a poleward shift of the Kuroshio current (Fig. 13). Both processes are explained by a positive tropospheric pressure anomaly over the North Pacific and are not dependent on the type of forcing (i.e., GHGs and aerosols). The close relationship between the forced high-pressure trend over the North Pacific and SST increase in the KR for 1951-2010 was also identified in the CMIP5 multi-model ensemble and the MIROC6 large ensemble. A comparison of the 1981-2010 linear trends in observations, atmospheric reanalysis data, and the ensemble-mean fields of MIROC5.2 HIST suggests that the highpressure trend over the North Pacific was a combination of the PDO-related internal variability and externally forced components.
In the CMIP5 multi-model ensemble, all but one model shows the high-pressure anomaly over the North Pacific when the KR SST increases. However, the position and the amplitude vary among models (Fig. 11b). Previous studies reported that the MME-mean Z500 exhibits high-pressure tendencies over the North Pacific in future projections (Hori and Ueda 2006; Kimoto 2005). Gan et al. (2017) showed a northward intensification of the Aleutian Low, accompanying a high-pressure anomaly in the mid latitude of the North Pacific, under the greenhouse warming due both to an El Niño-like SST warming pattern in the tropical Pacific and a positive tendency of the Arctic Oscillation. Thus, it seems that the high-pressure trend over the North Pacific observed for 1951-2010 is an emerging signal of global warming.

Our analyses highlight the effect of sulfate aerosol forcing on the rise of multidecadal changes in Z500 over the North Pacific. Although the mechanism for aerosols driving multidecadal pressure changes is unclear, this result is consistent with Boo et al. (2015) who showed SLP changes over the North Pacific forced by sulfate aerosols. Several studies suggest that the aerosol induced atmospheric changes over the North Pacific were remotely connected to SST changes 
(a)

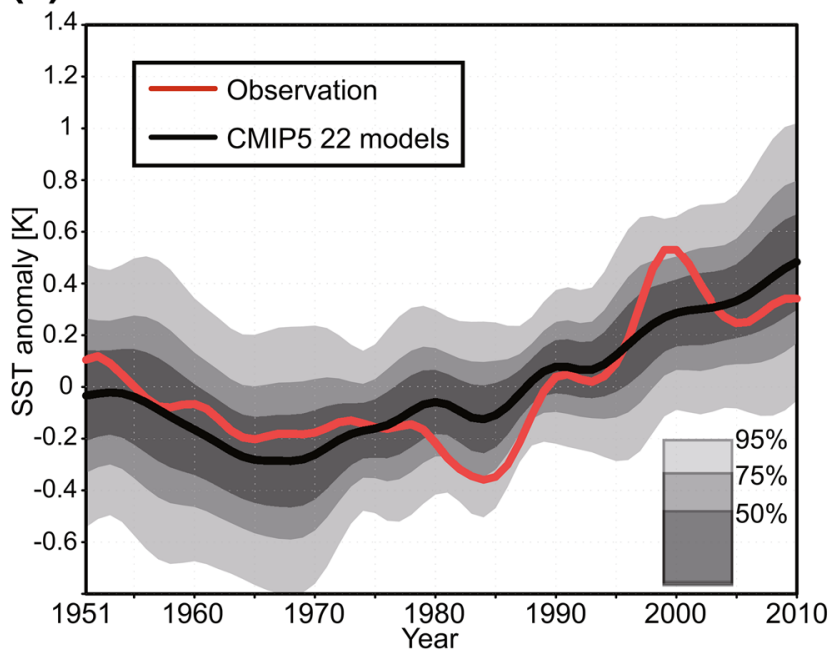

(c)

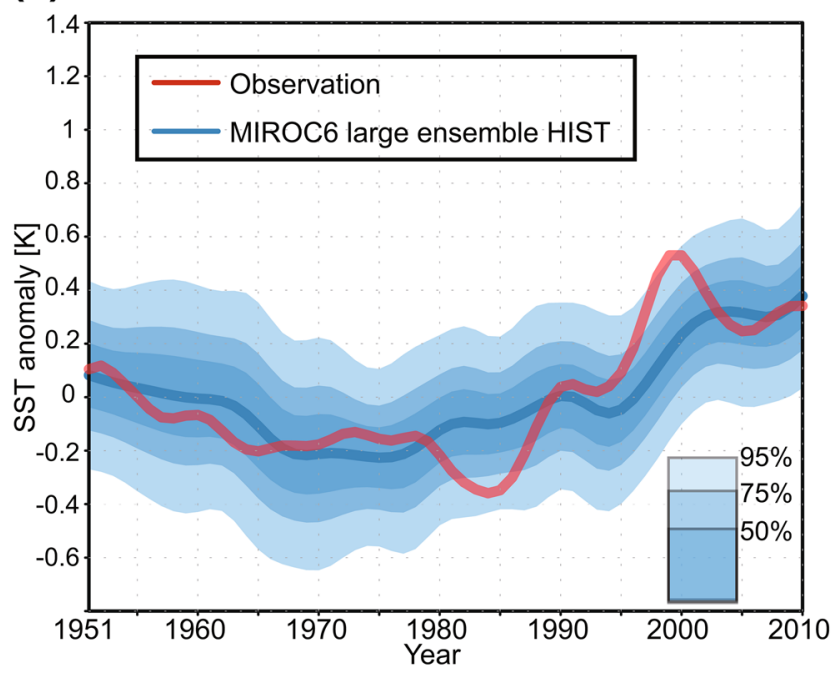

Fig. 11 a Time series of 10-year low-pass filtered sea surface temperature (SST) anomalies in the Kuroshio region (KR) from COBE-SST (red curve) and the CMIP5 multi-model mean (black curve). Colored shading indicates the 50,75, and 95\% confidence levels of the ensemble. b Scatter plot between the 1951-2010 trends in the KR SST and

in the Atlantic. This was where the phase of the Atlantic multidecadal variability was affected by volcanic forcing and anthropogenic sulfate aerosol emissions over the EuroAtlantic sector (Booth et al. 2012; Watanabe and Tatebe 2019). While sulfate aerosol emissions have continuously increased over east Asia, they are apparently not forcing multidecadal pressure changes over the North Pacific.

The attribution of forced changes in the Kuroshio current is still challenging. Ocean components of the CMIP5 models, including MIROC5.2, do not resolve oceanic eddies due to their coarse horizontal resolution. This leads to large errors in reproducing the Kuroshio current (b)

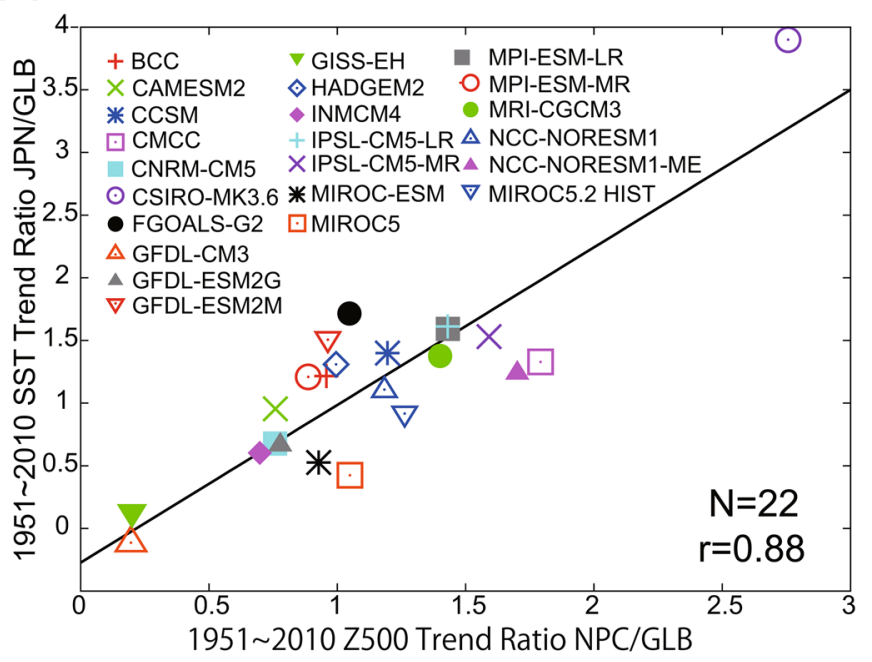

(d)

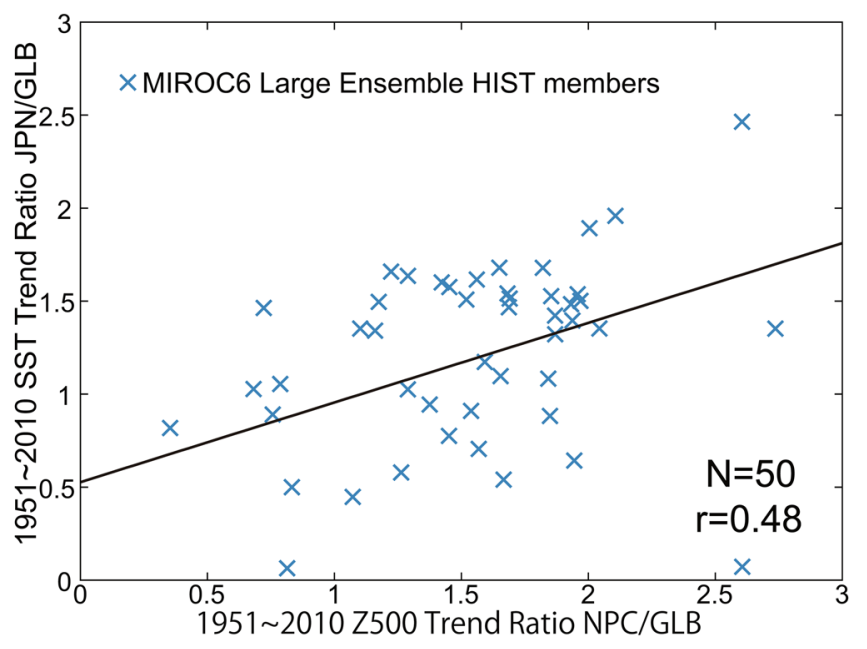

the North Pacific Z500 across 22 CMIP5 models. Both linear trends were scaled with the global-mean trends of the respective variable. The correlation coefficient is also shown in the panel. c, d As per (a, b) but for the MIROC6 large ensemble historical simulations

in the present climate. The enhanced SST increase due to a poleward shift of the Kuroshio current was concentrated to a narrow region in the northeastern KR, and it contains uncertainty. In addition to the challenges in reproducing western boundary currents using GCMs, ocean reanalysis data are less reliable than the atmospheric reanalysis, hampering observational analysis of past changes in the Kuroshio current. To acquire a better understanding of the Kuroshio's response to radiative forcing, it is necessary to carry out ensemble historical runs using high-resolution GCMs that resolve oceanic eddies. Such simulations will be available in future studies. 
(a)

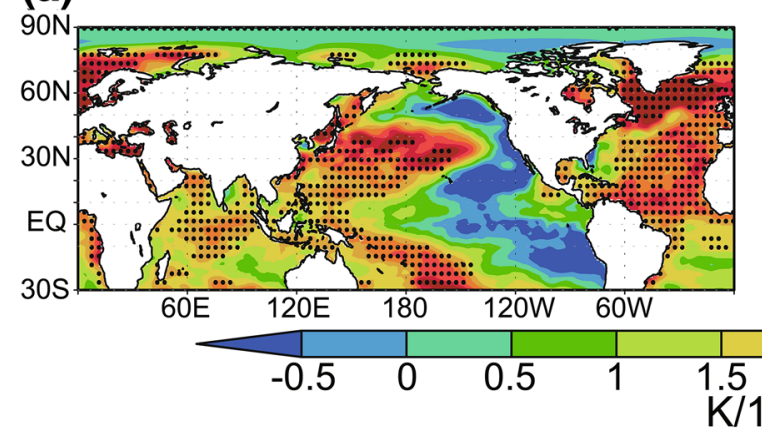

(c)

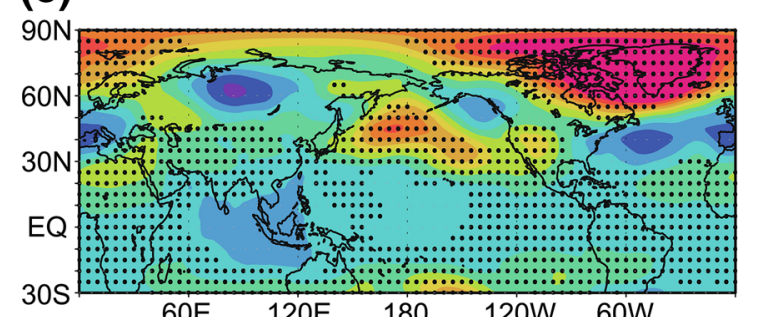

(b)

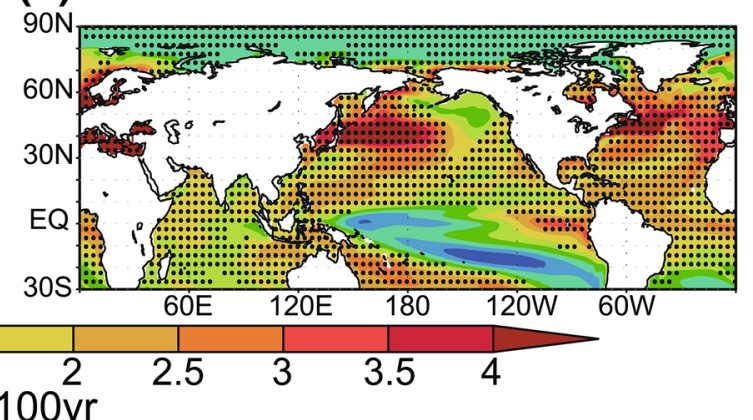

(d)

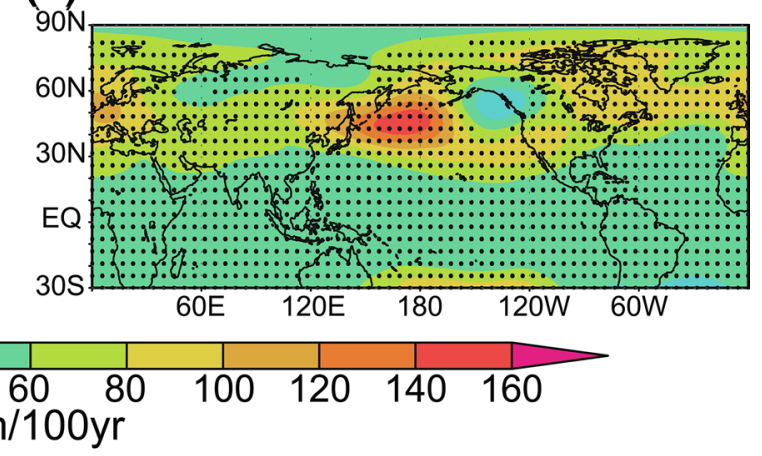

Fig. 12 a, b Sea surface temperature (SST) trends for 1981-2010 from COBE-SST and the ensemble mean of HIST. c, d As per (a, b), but for Z500 from JRA-55 and the HIST ensemble mean

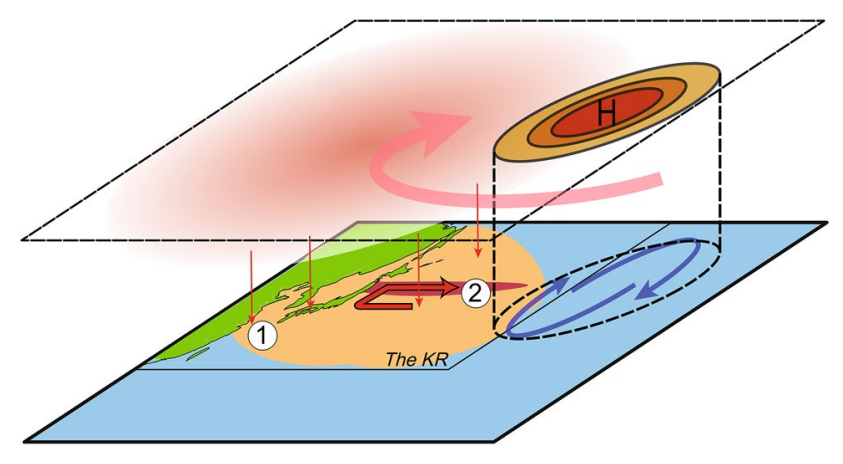

Fig. 13 A schematic diagram depicting mechanisms of forced sea surface temperature (SST) increase in the Kuroshio region (KR) found in this study. Two major processes are labelled (1) and (2); (1) represents extensive enhancement of SST (orange shade) by warm temperature advection in the lower troposphere that transport heat to the ocean via sensible heat flux (thin red arrows) and (2) indicates a local enhancement of the SST (wine red shade) increase caused by the poleward shift of the Kuroshio current associated with a negative stress curl (think pink arrows). Both processes are induced by the tropospheric high-pressure tendency over the North Pacific (ellipse in the upper panel labelled ' $\mathrm{H}$ ')

Acknowledgements We would like to thank Yu Kosaka and Youkou Yamagami for their constructive comments. Thanks also to Hiroaki Tatebe for providing the MIROC6 large ensemble data. This work was supported by the Grant-in-Aid for Scientific Research 19H01962 and the Integrated Research Program for Advancing Climate Models from the Ministry of Education, Culture, Sports, Science and Technology (MEXT), Japan.

Open Access This article is licensed under a Creative Commons Attribution 4.0 International License, which permits use, sharing, adaptation, distribution and reproduction in any medium or format, as long as you give appropriate credit to the original author(s) and the source, provide a link to the Creative Commons licence, and indicate if changes were made. The images or other third party material in this article are included in the article's Creative Commons licence, unless indicated otherwise in a credit line to the material. If material is not included in the article's Creative Commons licence and your intended use is not permitted by statutory regulation or exceeds the permitted use, you will need to obtain permission directly from the copyright holder. To view a copy of this licence, visit http://creativecommons.org/licenses/by/4.0/.

\section{References}

Andrews T, Gregory JM, Webb MJ (2014) The dependence of radiative forcing and feedback on evolving patterns of surface temperature change in climate models. J Clim 28:1630-1648

Boo K-O, Booth BBB, Byun Y-H, Lee J, Cho CH, Shim S, Kim K-T (2015) Influence of aerosols in multidecadal SST variability simulations over the North Pacific. J Geophys Res Atmos 120:517-531

Booth BB, Dunstone NJ, Halloran PR, Andrews T, Bellouin N (2012) Aerosols implicated as a prime driver of twentieth-century North Atlantic climate variability. Nature 484:228-232 
Chadwick R, Good P, Andrews T, Martin G (2014) Surface warming patterns drive tropical rainfall pattern responses to $\mathrm{CO}_{2}$ forcing on all timescales. Geophys Res Lett 41:610-615. https://doi. org/10.1002/2013GL058504

Collins $\mathrm{M}$ et al (2010) The impact of global warming on the tropical Pacific Ocean and El Nino. Nat Geosci 3:391-397

Eyring V et al (2016) Overview of the coupled model intercomparison project phase 6 (CMIP6) experimental design and organization. Geosci Model Dev 9:1937-1958

Gan B, Wu L, Jia F, Li S, Cai W, Nakamura H, Alexander MA, Miller AJ (2017) On the response of the Aleutian low to greenhouse warming. J Clim 30(10):3907-3925

Hori ME, Ueda H (2006) Impact of global warming on the East Asian winter monsoon as revealed by nine coupled atmosphere-ocean GCMs. Geophys Res Lett 33:L03713. https://doi. org/10.1029/2005GL024961

IPCC (2013) Climate change 2013: the physical science basis. In: Stocker TF, et al. (eds) Contribution of working group I to the fifth assessment report of the intergovernmental panel on climate Change. Cambridge University Press, Cambridge, p 1535

Ishii M, Shouji A, Sugimoto S, Matsumoto T (2005) Objective analyses of sea-surface temperature and marine meteorological variables for the 20th century using ICOADS and the Kobe Collection. Int J Climatol 25(7):865-879

Japan Meteorological Agency (2018) Bulletin of climate monitoring 2017 (in Japanese). Available at https://www.data.jma.go.jp/cpdin fo/monitor/

Kimoto M (2005) Simulated change of the east Asian circulation under global warming scenario. Geophys Res Lett 32:L16701. https:// doi.org/10.1029/2005GL023383

Kobayashi et al (2015) The JRA-55 reanalysis: general specifications and basic characteristics. J Meteorol Soc Jpn Ser II 93:5-48

Liu Q, Xie S-P, Li L, Maximenko NA (2005) Ocean thermal advective effect on the annual range of sea surface temperature. Geophys Res Lett 32:L24604. https://doi.org/10.1029/2005GL024493

Rayner N et al (2003) Globally complete analyses of sea surface temperature, sea ice and night marine air temperature since the late nineteenth century. J Geophys Res 108:4407

Saenko OA, Fyfe JC, England MH (2005) On the response of the oceanic wind-driven circulation to atmospheric $\mathrm{CO}_{2}$ increase. Clim Dyn 25:415-426
Sakamoto TT, Hasumi H, Ishii M, Emori S, Suzuki T, Nishimura T, Akimasa A (2005) Responses of the Kuroshio and the Kuroshio extension to global warming in a high-resolution climate model. Geophys Res Lett 32:L14617. https://doi.org/10.1029/2005G L023384

Smith TM, Reynolds RW, Peterson TC, Lawrimore J (2008) Improvements to NOAA's historical marged Land-Ocean surface temperature analysis (1880-2006). J Clim 21:2283-2296

Takahashi C, Watanabe M (2016) Pacific trade winds accelerated by aerosol forcing over the past two decades. Nat Clim Change 6:768-772

Tatebe $\mathrm{H}$ et al (2019) Description and basic evaluation of simulated mean state, internal variability, and climate sensitivity in MIROC6. Geo Model Dev 12:2727-2765

Taylor KE, Stouffer RJ, Meehl GA (2011) An overview of CMIP5 and the experiment design. Bull Am Meteorol Soc 93:485-498

Watanabe M, Tatebe H (2019) Reconciling roles of sulphate aerosol forcing and internal variability in Atlantic multidecadal climate changes. Clim Dyn. https://doi.org/10.1007/s00382-019-04811-3

Watanabe M, Shiogama H, Tatebe H, Hayashi M, Ishii M, Kimoto M (2014) Contribution of natural decadal variability to global warming acceleration and hiatus. Nat Clim Change 4:893-897

Wu et al (2012) Enhanced warming over the global subtropical western boundary currents. Nat Clim Change 2:161-166

Xie S-P, Deser C, Vecchi GA, Ma J, Teng H, Wittemberg AT (2010) Global warming pattern formation: sea surface temperature and rainfall. J Clim 23:966-986

Xie S-P, Lu B, Xiang B (2013) Similar spatial patterns of climate responses to aerosol and greenhouse gas changes. Nat Geosci 6:828-832

Publisher's Note Springer Nature remains neutral with regard to jurisdictional claims in published maps and institutional affiliations. 